\title{
Alergias alimentarias
}

\section{Food allergies}

Vicente J. Gutiérrez Coronado: Universidad de Alcalá de Henares. Madrid (España) vicente-gc@uah.es

Juan Manuel Díaz Barrera: Universidad de Alcalá de Henares. Madrid (España) jm.diazbarrera@uah.es

\section{CURRÍCULUM VITAE}

Doctor en Farmacia por la Universidad de Alcalá de Henares (España). Profesor en el área de Farmacia y Tecnología Farmacéutica en la Facultad de Farmacia de la Universidad de Alcalá de Henares (España). Autor de varios artículos científicos en revistas universitarias y técnicas.

Licenciado en Farmacia por la Universidad de Alcalá de Henares (España).

\section{RESUMEN}

El sistema inmunitario está formado por una compleja red estructural de células y moléculas especializadas en diferentes funciones y distribuidas por todo el organismo. La característica distintiva de este sistema es la capacidad de reconocimiento específico de fragmentos moleculares, que conlleva el establecimiento de interacciones constantes entre sus componentes con los distintos sistemas que forman el organismo y con los posibles elementos extraños que puedan penetrar en el mismo. Esta capacidad de reconocimiento, seguido de la activación 
celular y el desarrollo de los mecanismos efectores, le concede al sistema inmunitario una función relevante entre los mecanismos de defensa del organismo frente a las infecciones. El Sistema Inmunitario apareció cuando los vertebrados evolucionaron de las primitivas formas invertebradas, tras lo cual ocurre el hecho notable de que dicho sistema compone el fin exclusivo de defender el organismo contra la infección. En este texto se presenta un estudio profundo y detallado de los antecedentes, el sistema inmunitario, cómo funciona, las reacciones, las alergias, los alimentos como tóxicos potenciales, entre otros análisis.

\title{
PALABRAS CLAVE
}

Sistema Inmunitario - Organismo - Alergias - Alimentos

\begin{abstract}
The immune system consists of a complex structural network of specialized cells and molecules in different functions and distributed throughout the body. The distinguishing feature of this system is the ability of specific recognition of molecular fragments, which involves the establishment of ongoing interactions between its components with the various systems that make up the body and potential foreign elements that can penetrate it. This ability of recognition, followed by cell activation and development of effector mechanisms, the immune system gives a significant role among the body's defense mechanisms against infections. The Immune System appeared when vertebrates evolved from primitive invertebrate forms, after which occurs the remarkable fact that this system comprises the sole purpose of defending the body against infection. This text presents a thorough and detailed study of the background, the immune system, how it works, reactions, allergies, and potential toxic food, among other analyzes.
\end{abstract}




\section{KEY WORDS}

Immune System - Body - Allergies - Food

\section{ÍNDICE}

1. Preliminares

1.1. Antecedentes evolutivos

1.2. Historia. Descubrimientos y avances

1.3. Sistema Inmunitario. Funciones de los Ac. Mecanismos

1.3.1. Base celular del sistema inmunitario

1.3.2. Bases moleculares del sistema inmunitario

1.4. Mecanismos de respuesta

1.5. Factores que conducen a enfermedad autoinmune

1.6. Reacciones de Hipersensibilidad: Alergias

1.7. Alergias. Clasificación

2. El alimento como tóxico potencial

2.1. Relación del alérgeno en la generación de autotoxicidad

2.2. Descripción del alérgeno

2.3. Epidemiología. Efectos e Incidencias en la población

2.4. El factor idiosincrásico y la predisposición genética

3. Alergias alimentarias

3.1. Clasificación de los principales Alérgenos

3.2. Pruebas Diagnósticas

3.3. Interpretación de resultados: Diagnosis

3.4. Cuadros clínicos de Intolerancias y Alergias

3.4.1. Leche de vaca

3.4.2. Sensibilidad al gluten y Enfermedad Celíaca

4. Nuevas expectativas y tendencias actuales 


\subsection{Errores Dietéticos}

4.2. Avances en el estudio de pruebas diagnósticas

\subsection{Repercusiones económicas}

5. Bibliografía

TEXTO:

\section{Preliminares}

Inmunología

\subsection{Antecedentes evolutivos}

El sistema inmunitario está formado por una compleja red estructural de células y moléculas especializadas en diferentes funciones y distribuidas por todo el organismo. La característica distintiva de este sistema es la capacidad de reconocimiento específico de fragmentos moleculares, que conlleva el establecimiento de interacciones constantes entre sus componentes con los distintos sistemas que forman el organismo y con los posibles elementos extraños que puedan penetrar en el mismo. Esta capacidad de reconocimiento, seguido de la activación celular y el desarrollo de los mecanismos efectores, le concede al sistema inmunitario una función relevante entre los mecanismos de defensa del organismo frente a las infecciones y neoplasias. Además, sus alteraciones se pueden implicar y relacionar en la patogenia de diferentes enfermedades.

La especie humana ha existido en una forma muy parecida a la actual durante unos 200.000 años; en ese tiempo cabe suponer que el sistema inmunitario ha 
desempeñado un papel decisivo en nuestra capacidad de resistir la exposición a los diferentes antígenos que, por evolución conjunta y mutua se ha ido estructurando.

Ciertos cambios sucedidos en aspectos clave de las condiciones de vida de la humanidad ha hecho que los desafíos actuales de nuestro sistema inmune sean más terribles que nunca: la industrialización, el entorno artificial, el crecimiento y expansión demográfica, son casos que ilustran la facilidad con que las personas quedan expuestas a la acción de los patógenos. Además, la tendencia y frecuencia de aparición de especies y cepas o fragmentos moleculares cambiados de patógenos, constituyen otra de las dificultades a las que se ha de enfrentar la ciencia y nuestro sistema inmune.

Es entonces importante buscar en los albores de la historia evolutiva del sistema inmunitario, unos aconteceres que justifican dicha coevolución:

El Sistema Inmunitario apareció cuando los vertebrados evolucionaron de las primitivas formas invertebradas, tras lo cual ocurre el hecho notable de que dicho sistema compone el fin exclusivo de defender el organismo contra la infección, este hecho es confirmado en los rarísimos casos en los que nacen niños con un sistema inmune deficitario y no funcional por causa de una mutación de un gen decisivo: si no reciben tratamiento que les aísle adecuadamente, morirán de cualquier infección.

Además de la unicidad de su misión, la consideración de la historia del sistema inmunitario nos revela un segundo rasgo fundamental: la evolución de este sistema ha seguido un proceso de elaboración, por incorporación y mejora de los precarios sistemas de defensa de los invertebrados, como son los fagocitos circulantes y las proteínas de acción inmunitaria inespecífica. Estas defensas ancestrales carecían de memoria específica, nota distintiva de un sistema inmunitario propiamente dicho. En este sentido, entre las mejoras que la evolución ha proporcionado se encuentran las 
Células Presentadoras de Antígeno, o el Sistema del Complemento: hay formas que aún conservamos (receptores del complemento en la membrana de los linfocitos) y otras que se han mejorado (moléculas del Complejo Principal de Histocompatibilidad -M.H.C.- que expresan los macrófagos).

Paralelamente a esta evolución, también supuso la del Sistema Nervioso, en la especialización de cada grupo de funciones, llevadas a cabo por regiones muy concretas del mismo y exquisitamente interrelacionadas, tanto para si mismo como para todo el resto de las estructuras del organismo y el sistema inmunitario.

Casi todos los avances decisivos acontecieron, según parece, en una fase muy primitiva de la evolución de los vertebrados, estadio que se halla escasamente representado en el registro fósil y del cual sobreviven pocas especies:

Hasta los vertebrados más primitivos de los hoy existentes parecen reordenar sus genes codificantes de los receptores de antígenos y poseer células T y B distintas, así como moléculas de M.H.C. Pero para el caso de las inmunoglobulinas, se pueden discernir bastantes vestigios de una secuencia evolutiva: el sistema se perfecciona a partir de un único gen productor de inmunoglobulina que, por duplicación, originó las distintas secuencias de inmunoglobulinas, tras lo cual emergen los mecanismos de control que confirieron la capacidad recombinatoria y aseguran la total especificidad de unión antígeno-anticuerpo. He aquí otro punto importante: la Especificidad; las proteínas del sistema inmunitario se han diversificado y especializado hasta un punto sin precedentes, excepto en el sistema nervioso, y resulta sorprendente que las amplísimas posibilidades de combinación se establecen con un número muy limitado de elementos proteicos, que son las porciones variables de las cadenas de Ig. 
A medida que el sistema inmunitario fue ganando en importancia y complejidad, sufrió una serie de reorganizaciones internas de diverso tipo, debido a que los recursos metabólicos de un organismo obliga a estas operaciones de economía sin menoscabo de la efectividad: los sistemas efectores deben su función intrínseca a complejos sistemas reguladores, tal es el caso de las células CD4 -cél. T reguladoras-, que abundan más que células de cualquier otra clase.

Pero el proceso evolutivo no se ha cerrado, de hecho evoluciona con gran celeridad y ello es debido a que la afectación es a los genes polimórficos, los cuales expresan muchas formas distintas de la misma molécula de M.H.C. o anticuerpo; el sistema inmunitario es intensamente polimórfico hasta tal punto que una determinada combinación difícilmente aparece duplicada; hecho favorecido aun más en individuos heterocigotos, pues de los distintos loci genéticos ocurre que poseen dos genes diferentes en cada locus, lo cual eleva las posibilidades de engarzarse a un péptido al menos de cada proteína vírica o bacteriana. En el caso del polimorfismo del M.H.C., reviste mayor complejidad debido a que la probabilidad conduce a productos que pueden llegar a suprimir la respuesta inmune, y así amortiguan la respuesta drástica y desenfrenada que dañaría al propio organismo en el transcurso de las reacciones; son los fenómenos de Hipersensibilidad y Alergias y otros transtornos autoinmunitarios. De cualquier modo, la presencia de estos genes proporciona, accidentalmente, protección contra enfermedades de tipo crónico dependientes de los transtornos autoinmunitarios antes mencionados, aunque está garantizado por la dependencia de unas citocinas inhibidoras tales como el T.G.F.Beta.

Por todo lo expuesto anteriormente, la evolución, perfil y acondicionamiento de los mecanismos inmunitarios a través del tiempo es un claro ejemplo de la coevolución recíproca entre hospedador y factores conducentes a enfermedades o patologías: esta 
evolución compartida asegura el delicado y sutil equilibrio entre la barrera del concepto de Salud y Enfermedad.

\subsection{Historia. Descubrimientos y avances}

La unidad básica y elemento crucial del sistema inmunitario es el Anticuerpo, una proteína de gran tamaño descubierta por Von Behring y S. Kitasato en 1890. Los anticuerpos detectan y neutralizan los invasores extraños, recubren los patógenos con sustancias "apetecibles" para los macrófagos activados y poseen la característica de ser específicos para su Antígeno. Como base de las primeras teorías, F. Haurowitz en 1930 pensó que el antígeno servía de molde para el anticuerpo, el cual adoptaba una forma complementaria al Ag. Esta teoría se sostuvo hasta que, mediados los años 60, G. L. Ada y cols. demostraron que las células productoras de Ac. no contenían Ag. alguno alrededor del cual adquiriese su forma el Ac.: por determinaciones estructurales y cristalográficas de las enzimas se estableció que la estructura de una proteína dependía exclusivamente del orden preciso en que están secuencializados los aminoácidos que la constituyen. Paralelamente, F. Crick concluyó que la información fluye en los sistemas biológicos del DNA al RNA y de éste a la proteína. Por esta razón, las proteínas antigénicas no podían definir nuevas proteínas de anticuerpos, sino que la información de las estructuras de los Ac. tenían que estar codificados en los genes. Para explicar el aparente contrasentido de la diversidad de Ac. diferentes a partir de unos genes concretos, N. Jerne en 1955 apuntó que dicha diversidad se debe a unos principios de selección no de información, es decir, capacitación de acelerar la formación del Ac. que encaje con el Ag. a partir de multitud de anticuerpos formados durante la etapa de estimulación. En 1957, Burnet y D. Talmage establecieron la hipótesis de que los Ac. se asientan sobre la superficie de los linfocitos y cada linfocito lleva sólo un tipo de Ac. cuando un Ag. extraño penetra en el organismo, acabará encontrando un linfocito que posea el receptor en el 
que encaje, estimulando químicamente un complejo sistema de respuesta. Estudios posteriores evidenciaron esta hipótesis.

G. Edelman y R. Porter, descubrieron que los Ac. están compuestos por cuatro proteínas pequeñas llamadas cadenas: cada Ac. posee dos cadenas pesadas iguales y dos cadenas ligeras iguales también. El entrelazado de una cadena pesada y una ligera confiere un sitio activo capaz de reconocer específicamente un Ag. Entonces cada molécula de Ac. tiene dos sitios de reconocimiento idénticos. La enorme diversidad de Ac. se explica a partir de que sean dos las cadenas que intervienen en la formación del sitio de unión, pues el número de emparejamientos es muy elevado.

Evidencias estructurales obtenidas años más tarde, confirmaron y ampliaron el valor de estas hipótesis: los portadores de la información se hallan en cuatro conjuntos de minigenes localizados en partes del núcleo distantes y la diversidad de los Ac. nace del tamaño de esas familias de minigenes: existen más de 100 tipos de genes $\mathrm{V}$ (variables), 12 genes D (diversidad) y 4 genes J (unión -"joining"-). Los genes C (constantes) varían de modo que solo afectan a la función del Ac. pero no a su afinidad antigénica.

Durante el desarrollo de una célula productora de anticuerpos, un miembro de cada uno de los conjuntos de minigenes se une a otro hasta formar un gen V-D-J-C completo: este reagrupamiento génico permite que se formen hasta 4.800 variedades diferentes $(100 \times 12 \times 4 \times 1)$ de cadenas pesadas. El mismo proceso tiene lugar en la formación de cadenas ligeras con la salvedad de que sólo tienen segmentos V, J, y C; en este caso, pues, las combinaciones básicas son 400. La diversidad de las cadenas pesadas y ligeras permite la existencia de 4.800×400, o sea, 1.920 .000 genes de Ac.; además, ciertas enzimas especiales pueden insertar unidades adicionales de DNA en las uniones entre los segmentos V y D ó D y J cuando éstos se enlazan, lo que de nuevo incrementa las posibilidades en la combinatoria de los Ac. sintetizables. 
En la actualidad la Inmunología tiende a la elucidación de mecanismos más complejos:

Investigación sobre células cancerosas, rechazos en los órganos transplantados, aspectos de investigación sobre procesos alergénicos, junto con la interconexión de este sistema con el resto de los sistemas del organismo, especialmente el hormonal y las señales que guían a las células madre a producir células inmunitarias de uno u otro tipo, son solo algunos ejemplos de la trayectoria inabarcable de este campo.

\subsection{Sistema inmunitario. Funciones de los anticuerpos. Mecanismos}

La eficacia exhibida por los Ac. para identificar moléculas extrañas y encauzar las defensas, le confiere la capacidad de eliminar la infección, resistir la reinfección y recibir la protección de la vacuna. Pero algunos de esos mismos mecanismos provocan, en ocasiones, la enfermedad en vez de controlarla: vemos así que el sistema inmunitario puede reaccionar ante sustancias extrañas inocuas y producir la alergia. Los acontecimientos pueden tomar un cariz más grave, cuando se atacan los propios tejidos y se desencadena una enfermedad autoinmune. Pero, en uno u otro caso, se sabe que los mecanismos de reconocimiento y de respuesta son los mismos. Veamos en qué consisten.

El organismo se vale de dos recursos principales para identificar el material extraño: el Sistema Inmunitario Innato y el Sistema Inmunitario Adaptativo. En el primero, el organismo nace con la capacidad de reconocer inmediatamente a ciertos microorganismos y destruirlos y, en el segundo, adaptativo, en que los anticuerpos desempeñan un papel sobresaliente, debido al proceso de selección clonal gracias a la capacidad polimórfica a la que antes nos hemos referido. 
El componente celular del sistema inmunitario está constituído por los linfocitos y por las células accesorias. Los linfocitos se clasifican en T, B y en las denominadas células citotóxicas espontáneas (NK). Entre las células accesorias, que están implicadas en la activación de los linfocitos, se incluyen los macrófagos, células dentríticas, de Langerhans, de Kupffer, etc. específicas de algunos tejidos. La base molecular está formada por el sistema del complemento, las inmunoglobulinas y las linfocinas y monocinas.

La actividad de los componentes celulares del sistema inmunitario está estrechamente relacionada con un grupo de moléculas expresadas en la membrana citoplasmática de las células nucleadas del organismo, conocidas genéricamente como M.H.C. -Complejo Principal de Histocompatibilidad- y que definen específicamente el tipo diferencial de tejido de un individuo.

Este Complejo Principal de Histocompatibilidad son una serie de estructuras antigénicas que diferencian a los individuos de una especie y es propio de un sistema génico concreto. El estudio del MHC está unido, históricamente al análisis de las implicaciones en el rechazo de los transplantes.

Hay tres clases diferentes:

Las moléculas de clase I, se encuentran en las membranas celulares de prácticamente todos las células nucleadas del organismo.

Las moléculas del MHC de clase II, se distribuyen en las membranas celulares de los Linfocitos B, de las células accesorias, de los Linfocitos $\mathrm{T}$ activados y de precursores inmaduros hematopoyéticos. 
Cabe destacar que las moléculas del MHC clase I y clase II se encuentran relacionadas evolutivamente a partir de un único gen ancestral.

La moléculas de clase III están constituídas por varios componentes del complemento. Se halla muy relacionada con TNF y linfotoxina, así como de agentes implicados en el control del crecimiento y desarrollo celular.

\subsubsection{Base celular del sistema inmunitario}

Los Linfocitos $\mathrm{T}$ recibieron esta denominación por su maduración intratímica durante la vida fetal y postnatal precoz. Representan del $60 \%$ al $70 \%$ de todos los linfocitos de la sangre periférica, aunque también se encuentran en otras localizaciones linfáticas y del bazo. Presentan en su membrana citoplasmática proteínas con diferente estructura y función, que permiten su identificación y caracterización fenotípica. Algunas de estas moléculas están implicadas en los procesos de reconocimiento específico del Ag. denominado TCR -complejo receptor de las células T-. También intervienen en la activación y adherencia celular y en otras cuestiones aun no bien definidas. Las células T (al contrario que las células B, de las que se hablará seguidamente) no pueden ser activadas por los Ag. solubles, precisan de activación para poder ser funcionales al sistema inmune.

Desde el punto de vista estructural, de la unión de las diferentes regiones variables y constantes, que conforman los Cluster Denominations (CDn) que son complejos moleculares monomórficos y constituyen los receptores, se origina gran polimorfismo, capaz de conseguir que la unión Ag.-Ac. sea específica. La síntesis de estos receptores es el resultado del reordenamiento de distintos segmentos génicos, como ya se comentó en el apartado anterior. Entre las proteínas CD importantes, se han detectado en diferentes clones de linfocitos unas moléculas que son idénticas a todos ellos y son CD3, CD2, CD4 y CD8. Éstas últimas, cuya expresión en la 
membrana es mutuamente excluyente, determinan dos subproductos de poblaciones de Linfocitos $\mathrm{T}$ y que determinan que la célula que las expresa tenga o el requerimiento o la restricción de reconocimiento del Ag. en presencia de las moléculas de la Clase I o de la Clase II del M.H.C. respectivamente: en líneas generales, existe una estrecha relación entre la función cooperadora/inductora linfocitaria T y la expresión del CD4 y la citotóxica/supresora con el CD8.

Los Linfocitos B recibieron esta denominación por el proceso de maduración en la Bursa de Fabricio en las aves o en su equivalente en los mamíferos: la médula ósea. Constituyen entre el $10 \%$ y el $20 \%$ de todos los linfocitos periféricos circulantes aunque están presentes en la médula ósea, en ganglios linfáticos, bazo o amígdalas y, órganos extralinfáticos como el aparato gastrointestinal.

En condiciones de reposo, sus características morfológicas son similares a las de los LT, excepto que presentan en su membrana citoplasmática Inmunoglobulinas de superficie, que constituyen un receptor antigénico. Tras la activación y maduración, inducida por el Ag. los LB se diferencian hacia células plasmáticas, con características morfológicas muy definidas y con capacidad de secreción de Ig's, como más tarde abordaremos.

Las Inmunoglobulinas poseen una estructura molecular básica formada por cuatro cadenas polipeptídicas: dos largas o pesadas y dos cortas o ligeras, idénticas entre sí. En cada una de ellas se identifica una porción variable, propia de cada clon de células B y otra constante común para cada uno de los cinco tipos de Ig's.

Es de reciente descubrimiento que, al igual que los LT con los genes que codifican la síntesis de su receptor antigénico, poseen reordenados en su genoma las regiones que codifican la síntesis de las diferentes porciones de su correspondiente Ig. 
Células Citotóxicas espontáneas

Estas células NK, Natural Killer, constituyen una subpoblación linfocitaria caracterizada por su morfología de núcleo arriñonado y con abundantes gránulos en su citoplasma, y por expresar en su membrana las moléculas monomórficas (CDn) que son receptores de fragmentos proteicos, además de compartir algunos receptores presentes en los LT. En la sangre periférica se hallan en un 10\% - 15\% de linfocitos. Hasta hace poco tiempo, eran conocidas como "células nulas", pues son no T no B. Presentan actividad natural lítica contra algunos tumores e infecciones víricas sin requerir una fase de sensibilización previa y sin estar restringida por las moléculas del M.H.C.

También ejercen funciones de regulación sobre las subpoblaciones de linfocitos y sobre células hematopoyéticas.

Monocitos / Macrófagos

Los macrófagos forman parte del sistema mononuclear fagocitario o sistema reticuloendotelial. Su diferenciación se produce en la médula ósea, con lo cual están estrechamente relacionadas con otras células (LT entre otras). Desde la médula ósea, los monocitos se dirigen al torrente circulatorio y de allí pueden migrar a los tejidos, transformándose en macrófagos, células fagocitarias de mayor tamaño, componiendo un reservorio importante allí durante la inflamación; pues la vida media de los monocitos es de un día y de los macrófagos, de varios meses. En los tejidos, se hallan distribuídos de forma difusa, aunque se localizan en ganglios linfáticos, órganos accesorios, pulmones y bazo.

La extravasación de los monocitos está controlada por moléculas de adhesión y mediadores químicos quimiotácticos y de activación. 
Los macrófagos además de la función fagocitaria, pueden ser activados, un proceso que hace que aumenten de tamaño, que se incrementen sus niveles de enzimas lisosómicas, que su metabolismo sea más activo y que se incremente su capacidad para fagocitar y destruir los microorganismos que ingiere. Entre las señales de activación se incluyen las citocinas, especialmente la secretada por los LT sensibilizados (IFN-gamma), endotoxinas bacterianas y proteínas del medio extracelular; así como otros mediadores químicos.

Una vez activados, secretan una amplia variedad de productos biológicamente activos, que median en la destrucción tisular, en la proliferación vascular, produciendo inflamación y cooperando activamente en la defensa inmunitaria; a saber:

1. Son necesarios para proceder y presentar el Ag. a las células T: son Células Presentadoras de Ag. (CPA). Puesto que las células T no pueden ser activadas por los Ag. solubles, la presentación del Ag. procesado y expuesto a la membrana de la CPA, es imprescindible para la inducción de la inmunidad celular.

2. Producen distintas citocinas, de las que algunas son proinflamatorias y también fibrogénicas.

3. Son importantes células efectoras en algunas formas de inmunidad celular, en fenómenos de Hipersensibilidad retardada. Como se indicó más arriba, las citocinas producidas por LT facilitan las funciones de los macrófagos.

\section{Células Accesorias}

Componen un grupo heterogéneo de células, constituídas por elementos con características morfológicas diferentes, tales como los monocitos/macrófagos, células 
dendríticas, células de Langerhans, células de Kupffer, etc. Por el contrario, comparten la expresión en su membrana citoplasmática de moléculas de clase I y clase II del M.H.C., así como de receptores para el fragmento Fc de la IgG y para componentes activados del Complemento.

Poseen característicamente, la capacidad de fagocitar Ag., procesarlos intracelularmente y expresar en la membrana citoplasmática sus determinantes antigénicos, en donde pueden ser reconocidos por los receptores clonotípicos de los LT. Asimismo, modulan la activación necesaria de los Linfocitos T y B por fenómenos de contacto físico directo y secreción de moléculas.

\subsubsection{Bases moleculares del sistema inmunitario}

Las Inmunoglobulinas o Anticuerpos, son moléculas producto de la diferenciación de los LB con capacidad de unión específica con el Ag. inductor de la activación del correspondiente clon B. Son formas solubles del receptor de LB), que al hallarse especificado por los mismos genes que crearon el receptor de la célula B original, este Ac. tendrá idéntica especificidad. Como antes hemos mencionado, las cinco clases de Ig's (IgG, IgA, IgM, IgD e Ig E) están constituídas por un par de cadenas pesadas idénticas y otro par de cadenas ligeras también idénticas, que se ensamblan por medio de puentes disulfuro adoptando una configuración espacial en forma de "Y". Asimismo, por mecanismos de elucidación enzimática se sabe que producen tres fragmentos: Dos idénticos, denominados Fab, constituída por la mitad aminoterminal de una cadena pesada unida a una ligera y un tercer fragmento denominado Fc, formado por las mitades carboxilo-terminales de las cadenas pesadas.

En el análisis funcional de las inmunoglobulinas, la capacidad de unión específica con mayor o menor afinidad al Ag. se localiza en el fragmento Fab, mientras que otras funciones biológicas residen en el fragmento Fc. El lugar de unión al Ag. es un 
hueco que se forma entre las regiones variables de ambas cadenas, y su grado de complementariedad molecular con aquel, determina la mencionada afinidad específica. Dentro de estas regiones variables existen regiones hipervariables, que son las que constituyen las paredes de la zona de la interacción con el Ag.

Las otras funciones biológicas de las Ig's, determinadas por dominios constantes de las cadenas pesadas incluyen la Activación del Complemento, la unión a las células fagocíticas, a los mastocitos y a los basófilos, y la capacidad de atravesar membranas del organismo por diapédesis.

Descripción de las IG's

\section{La IgG:}

Supone aproximadamente el 75\% del total de las Ig's séricas, existiendo varias subclases: IgG1 a IgG4.

Difunde a nivel de las membranas y es la única capaz de atravesar la placenta.

Esta IgG es la que suele predominar en la respuesta inmune inducida por la reexposición a un determinado Ag.

\section{La IgM:}

Posee una peculiaridad estructural (pentámero cuyos cinco miembros se hallan unidos por puentes disulfuro y un péptido de $15.000 \mathrm{D}$, que es una cadena J) que le confiere una gran eficiencia para activar el Complemento y la confina casi exclusivamente al espacio intravascular. 
Es la primera Ig. que aparece tras la exposición inicial a un Ag. y, en su forma monomérica de las membranas de las células $B$, constituye en relevante receptor antigénico de estos linfocitos.

\section{La IgA:}

Es la Ig predominante en las secreciones externas del organismo, apareciendo fundamentalmente como un dímero, sintetizado por las células epiteliales. Hay dos subclases en función del lugar en el que predominan -suero o secreciones-. Supone el 10\%-15\% de las Ig's séricas.

Activa el sistema del Complemento por la vía alternativa.

La IgD:

Está implicada en la regulación de la activación linfocitaria B.

Suele presentarse coexpresándose con la IgM, en la membrana de los LB

Se halla en concentraciones muy bajas, al igual que el número de células que la secretan.

\section{La IgE:}

Se caracteriza biológicamente por su capacidad de unirse por medio de la porción constante de su cadena pesada a basófilos y mastocitos, teniendo una vida media en el suero muy corta, con una concentración muy baja. Sin embargo, unida a sus receptores de membrana puede permanecer mucho tiempo y la interacción con el Ag. en estas condiciones determina el envío de una señal hacia el interior de estas 
células, lo que provoca su desgranulación inmediata y la liberación masiva de diversos mediadores de la respuesta inflamatoria.

Esta IgE es una de las causantes de que, en los individuos alérgicos actúen erróneamente contra sustancias inocuas, llegando incluso a producir síntomas mortales desencadenados por la liberación masiva de mediadores inflamatorios no bien controlados.

\section{Sistema del Complemento}

El complemento, descubierto por J. Bordet en 1.900, es un conjunto de proteínas séricas, que se sintetizan fundamentalmente en el hígado y que, al ser activadas interaccionan entre sí de forma secuencial, originando una serie de reacciones en cascada, con producción de diferentes fragmentos proteicos, capaces de ejercer diferentes efectos biológicos: lisis de membranas celulares, incremento de la eficacia fagocítica celular y la inducción de reacción inflamatoria. Se halla incluído pues, en lo que denominamos inmunidad innata.

El mecanismo de activación El mecanismo de activación sigue dos vías: Vía Clásica y Vía Alternativa:

En la primera, la activación tiene lugar por la unión del componente $\mathrm{C} 1$ a la región Fc de las IgM e IgG's, se escinden en cascada otros fragmentos, mediados por complejos C1-Ac., interviniendo diferentes convertasas sobre la fracción C3 y liberando, finalmente $\mathrm{C} 3 \mathrm{~b}$ que se une a la membrana constituyendo un grupo molecular de tres fragmentos del complemento y que poseen actividad sobre el C5.

En la vía alternativa, también se produce la activación del C3, en cuyo desencadenamiento inicial actúan algunos inductores como polisacáridos bacterianos 
o ciertos virus y parásitos. Por unión de fragmento C3b circulante se impide la inactivación de factores que de otro modo resultarían inhibidos. El complejo forma una convertasa que activa más C3 y además se une a otro fragmento de C3b formando ahora otra convertasa que activa al fragmento C5.

La convertasa del fragmento C5 formada por ambas vías escinde el fragmento C5, uno de los cuales se une a la membrana y determina el ensamblaje de cuatro componentes subsiguientes en la cascada formando un complejo con todos ellos, que se denomina Complejo de ataque a membrana (A1) y que determina la lisis.

Además de la formación del Complejo A1, se han generado en el proceso componentes con actividad biológica relevante y muy patente: Diversas células expresan en su membrana receptores para el fragmento $\mathrm{C} 3 \mathrm{~b}$, como es el caso de los monocitos-macrófagos, neutrófilos y eosinófilos, lo que favorece que estas células fagocíticas se adhieran con más eficacia a los elementos formes recubiertos por este componente del complemento, intensificando su capacidad fagocítica. Otras células, como los LB pueden expresar también receptores para $\mathrm{C} 3 \mathrm{~b}$, que al interaccionar con ellos modulan su activación y diferenciación hacia células plasmáticas secretoras de Inmunoglobulina. Los fragmentos C3a y C5a poseen una importante actividad quimiotáctica, fundamentalmente para los neutrófilos. Además, ambas moléculas tienen un notorio efecto sobre los mediadores de la inflamación, induciendo la contracción de la musculatura lisa, incrementando la permeabilidad vascular y provocando desgranulación de basófilos

Finalmente, baste considerar que las reacciones de activación del complemento están reguladas por algunas proteínas que bloquean la actividad enzimática de los primeros subcomponentes que inician la secuencia de reacciones.

Linfocinas y Monocinas 
El estado funcional de los linfocitos y de las células accesorias se regula exquisitamente por una serie de moléculas no-antígeno específicas llamadas Citocinas, que incluyen fundamentalmente a las linfocinas y monocinas.

Son moléculas que, segregadas por los Linfocitos o Monocitos, respectivamente, regulan la proliferación y diferenciación del sistema inmunitario. Estas moléculas se liberan tras la activación, que es el proceso mediante el cual la célula del sistema inmunitario interacciona con el Ag. y se desarrollan en el interior de la misma unas modificaciones bioquímicas que dan lugar a la síntesis de proteínas intercelulares, de membrana y secretoras. Tras la activación de monocitos y linfocitos tiene lugar la blastogénesis y/o producción de células efectoras, por cambio en los receptores de sus membranas, ya activados.

Se ha comprobado recientemente que ni la síntesis ni los efectos de las linfocinas y monocinas se limitan al sistema inmunitario, pueden regular la función de las células de otros órganos y tejidos, englobándose en el concepto general de citocinas, tal es el caso del T.G.F.-Beta, anteriormente mencionado; que ilustra el caso de la gran interrelación e integración de todos los sistemas y aparatos del cuerpo humano, así como de otros sistemas, de los que se ha demostrado una clara participación en la modulación, tales como el sistema nervioso y endocrino.

Se han descrito gran cantidad de factores, que se definieron por las funciones que eran capaces de promover o desempeñar, unificándose en este apartado cuando se logró conocer su composición química: algunas de ellas son las Interleucinas (ILn), que se identifican numéricamente:

IL-1, anteriormente denominada LAF -Factor Activador de Linfocitos- es secretada por células accesorias y otras como los LB, las células NK e incluso no pertenecientes al sistema inmunitario, pero que intervienen activamente en la inflamación. 
La secreción por el macrófago parece ser fundamental y depende de varias vías: una dependiente de la interacción con el LTcooperador (LTH), y otra por vía inespecífica: fragmentos del sistema del complemento, endotoxinas bacterianas, fragmentos víricos, otras citocinas, etc.

Entre sus funciones biológicas sobre el sistema inmune, cabe destacar la acción reguladora de la activación linfocitaria $\mathrm{T}$ y de la secreción de linfocinas. Sobre los LB induce señales de que favorecen la proliferación y su diferenciación hacia células secretoras de Ig's.

IL-2, se la ha denominado LGF -Factor de Crecimiento de Linfocitos T-. Su producción es exclusiva de los Linfocitos $\mathrm{T}$ y su acción es exclusiva del sistema inmunitario.

La actividad biológica es esencial en la regulación de la proliferación de los LT, así como de los LB y de su diferenciación hacia la secreción de Ig's. También activa los precursores citotóxicos de las Células NK, incrementando su actividad lítica.

IL-3, es una glicoproteína producida por los LT activados, capaz de mantener la proliferación de las distintas poblaciones de células del sistema inmunitario desde las células multipotenciales de la médula ósea.

No se ha detectado ninguna implicación de esta linfocina en la regulación del sistema inmunitario.

IL-4, actúa sobre los LB en reposo, modulando el efecto de activación subsiguiente a la interacción con el Ag. También ejerce un importante función en la regulación de la proliferación y diferenciación de los LB y LT. 
IL-5, actúa sobre la regulación de la diferenciación de los LB.

Posee una potente acción sobre la proliferación y maduración de los eosinófilos.

IL-6, que regula la diferenciación de los LB.

Sobre los hepatocitos, induce la síntesis de diferentes proteínas.

IL-7, inicialmente llamada Factor de Crecimiento de Células pre-B (PCGF) o Linfopoyetinas-1, que se produce en las células del estroma de la médula ósea y del timo.

Regula la maduración y proliferación de células T y B y sus precursores, los timocitos.

En ausencia de IL-2, posee acción citotóxica.

IL-8, o NAF-1 -Factor Activador de los Neutrófilos-. Es producida por una amplia variedad de células como monocitos, fibroblastos y células endoteliales tras la estimulación con otras señales, incluyendo la IL-1, TNF, endotoxinas y diferentes virus.

Su papel es primordial en la iniciación de la respuesta inflamatoria al promover la quimiotaxis y desgranulación posterior de neutrófilos. También es quimiotáctica sobre los LT y los basófilos, sobre estos últimos estimula la liberación de histamina.

IL-9, también conocida por P-40, descrita recientemente. 
Su acción se integra sobre distintas células diana, como los LTH y mastocitos estimulando selectivamente su proliferación.

IL-10, denominado originariamente Factor inhibidor de la síntesis de citocinas.

Su función parece que tiene que ver con la estimulación de células T y B tanto maduras como inmaduras.

IL-11, se produce en las células del estroma de la médula ósea y modula la diferenciación de los LB y de los precursores hematopoyéticos.

Otras IL de reciente denominación:

Factor de Necrosis Tumoral (caquectina). En el sistema inmunitario, regula la activación de los macrófagos, y la proliferación y maduración de los linfocitos T y B.

Estrechamente relacionado con el anterior, desde el punto de vista estructural y funcional, se encuentra la linfotoxina que compite por el mismo receptor del TNF.

Otro grupo importante de citocinas, con función muy relevante en el sistema inmunitario es el grupo molecular del Interferón (IFN), cuya clasificación se debió a diferentes criterios, de los cuales el aceptado en la actualidad lo divide en tres clases de IFN: IFN-alfa, IFN-beta e IFN-gamma.

IFN-alfa e IFN-beta forman el IFN de tipo 1, conocido así durante largo tiempo. Son bastante homólogos estructuralmente.

Los producen preferentemente los leucocitos y fibroblastos, respectivamente y regulan la función de diferentes células del sistema inmune: LT, LB y NK. 
IFN-gamma, es secretado por los linfocitos y las células NK y se denominó anteriormente como IFN de tipo 2 o inmune.

La acción inmunorreguladora de esta linfocina también es muy amplia, análoga a otros IFN's.

El Factor Transformante del Crecimiento beta (TGF-Beta), es otra linfocina secretada por LT y LB, en estos casos la acción que ejerce es inhibir su proliferación dependiente de IL-2 y en los LB además, también inhibe la secreción de Ig's.

Para terminar, y como todas las Linfocinas y Monocinas, su función no está solo relacionada con el sistema inmunológico, sino que actúan sobre órganos y tejidos muy diversos, incluso mediados por neuropéptidos y hormonas, en tales casos pueden activar o inhibir en función de la secuencia de reacciones en las que estén implicados en tales tejidos.

\subsection{Mecanismos de respuesta. Acciones del sistema inmunitario}

Como se ha descrito previamente, los Linfocitos constituyen un amplio grupo celular, caracterizados por expresar en su membrana citoplasmática receptores polimórficos, distribuídos en ella de forma clonal. Asimismo, se caracterizan por su capacidad de interaccionar específicamente con un determinado Ag. El desarrollo de la respuesta inmunitaria tras la activación inducida por un Ag. incluye al complejo proceso por el cual los linfocitos estimulados específicamente por éste proliferan y se diferencian hacia células efectoras. La mayor parte de los LT y LB presentes en el organismo en un momento concreto, se hallan en un estadio de reposo. La exposición a un Ag. induce la activación de algunos clones linfocitarios y su avance a través del ciclo celular, proceso que solo ocurrirá tras la necesaria activación. La estrategia celular de ambos tipos celulares define la efectividad de una respuesta que, en grado 
extremo o desproporcionado y bajo ciertas condiciones pueden ser causa de procesos alérgicos.

Los vertebrados superiores detectan y destruyen a los invasores de muy diversas formas, algunas muy inespecíficas se basan en la existencia de cantidades no habituales de sustancias que no son producidas en el organismo y, en caso de serlo, ocurre en muy pequeña proporción: los mamíferos detectan la presencia de bacterias invasoras porque éstas sintetizan péptidos que comienzan por un aminoácido desacostumbrado, la formilmetionina, que los mamíferos producen solo en pequeñas cantidades, cosa que estimulará la atracción de los neutrófilos. Asimismo el organismo detecta la presencia de virus porque éstos sintetizan grandes cantidades de ARN bicatenario, al contrario que los mamíferos.

Además, existen también mecanismos que identifican invasores específicos: en tal caso el organismo tiene que reconocer productos extraños cuya estructura química apenas si difiere de la de sus propias moléculas: esto se trata de conseguir por receptores presentes en las células inmunitarias por excelencia: los linfocitos; y los mecanismos de respuesta inespecíficas complementan a éste último, dada la complejidad. Veamos éstos procesos:

Los procesos de la Inmunidad adaptativa conforman el complemento ideal a los mecanismos de Inmunidad innata, ya descritos, debido a que el organismo puede discernir entre lo propio y lo ajeno, en función de la expresión en la superficie externa de la membrana de todas las células, de proteínas del Sistema Mayor de Histocompatibilidad (M.H.C.). En los procesos de inmunidad adaptativa, en última instancia se producirán Ac. que desplegarán en la superficie celular, cumpliendo éstos últimos funciones de receptor. Cada célula B (LB) sintetiza un receptor diferente, según un proceso de ensamblaje que fomenta la diversidad según lo ya explicado; por lo que cada una reconoce una molécula extraña distinta. De este 
modo, las células B se encuentran en la circulación, en reposo (ciclo celular G0), hasta la aparición de organismos o moléculas antigénicas, en cuyo caso, las células B se dividirán rápidamente en la etapa de proliferación. Todas las células B hijas proceden de la misma célula parental, por ello se las denomina clón: todas las células del mismo clón poseen el mismo receptor. Estos clones se diferencian, se especializan, en la maduración y posteriormente en células que segregan anticuerpos, que al igual que las células B en si mismas, se unirán al Ag, o determinantes antigénicos (porciones localizadas que identifican al cuerpo o fragmento molecular extraño). Los Ac. opsonizan al Ag., que es sinónimo de "marcar" al Ag., tras lo cual los fagocitos y el sistema del complemento lo eliminarán: este es el nexo de unión entre la inmunidad innata y adaptativa o, lo que es lo mismo Inmunidad humoral e inmunidad celular, respectivamente.

Como ya se mencionó, la diversidad se debe básicamente a tres aspectos como demostró F. Alt y D. Baltimore en 1.980: el primero de ellos a que enzimas que combinan segmentos génicos, añaden al azar bases de DNA a los extremos de la cadena obteniéndose nuevos genes que codificarán cadenas proteicas. La diversidad se incrementa aún más durante el ensamblaje de las cadenas proteicas en un receptor que forma el Ac. Para mayor diversidad, los genes que determinan los receptores de los LB mutan con suma rapidez cuando la célula B es activada por la unión a un Ag.: estas "hipermutaciones" crean nuevos receptores; de esta forma se optimiza el sistema inmune estableciendo sin cesar ligeras variaciones sobre los receptores ya satisfactorios.

De este modo, las células B pueden modificar los Ac. por reordenación de su estructura.

El organismo está protegido por un grupo heterogéneo de células y moléculas que funcionan coordinadamente. El objetivo final de la respuesta inmunitaria es el 
antígeno. Células presentadoras de Ag. (CPA) como los macrófagos, fagocitan estos Ag. y los fragmentan en péptidos antigénicos. Algunos de estos fragmentos se unen a moléculas del MHC y son presentados en la superficie celular. Otros leucocitos, los $\mathrm{LT}$, poseen moléculas receptoras que les permiten reconocer esos fragmentos peptídicos unidos al MHC, y se activan. La células T, activadas por este reconocimiento, se dividen y segregan linfocinas, que movilizan otros componentes del sistema inmunitario. Las células que responden a estas señales son los LB, que poseen en su superficie moléculas receptoras de especificidad única. A diferencia de los receptores de las células $\mathrm{T}$, los de las células $\mathrm{B}$ reconocen parte de los Ag's que se encuentran libres en disolución, no vinculados a moléculas del MHC. Una vez activadas, las células B se dividen y determinan en células plasmáticas que segregan unas proteínas, los Anticuerpos, que son formas solubles de sus receptores. Al unirse a los Ag's que encuentran, los Ac. pueden neutralizarlos o precipitar su destrucción por las enzimas del complemento o por las células del sistema inmunitario innato. Algunas células $\mathrm{T}$ y $\mathrm{B}$ se convierten en células con memoria que persisten en la circulación y estimulan el sistema inmune para eliminar el mismo Ag. si éste se presentara en un futuro. Debido a que los genes de los Ac. en las células B están sujetos a frecuentes mutaciones, la respuesta de los Ac. mejora después de inmunizaciones repetidas.

Como de la eficacia de los mecanismos inmunitarios depende, en gran medida de una excelsa coordinación, cabe plantear cómo están centralizadas las defensas en nuestro organismo:

Los agentes infecciosos pueden penetrar en el organismo por cualquier punto, por ello, los tejidos y órganos del Sistema Linfático -el hontanar de la defensa inmunitaria- están ampliamente distribuídos. Los linfocitos, responsables de la respuesta específica, se originan en los órganos linfoides primarios o centrales: el Timo produce células T y la médula ósea, células B; originan pues, la maduración de 
las células inmunocompetentes Tras abandonar dichos órganos, éstos circulan por la sangre hasta que llegan a alguno de los órganos linfoides secundarios o periféricos ganglios linfáticos, bazo, amígdalas, apéndice, placas de Peyer, adenoides, en orden de importancia-. Ahí abandonan la sangre a través de las vénulas de endotelio alto. A pesar que la densidad de linfocitos es bastante elevada (106 por 1gr de ganglio linfático), siguen moviéndose con cierta libertad. Por consiguiente, los ganglios son lugares excelentes para la activación de los linfocitos por los Ag's y por las CPA que penetran a través de los vasos linfáticos aferentes. Las células B activadas se transforman en células plasmáticas productoras de Ac.'s en áreas tales como los centros germinales de los folículos linfoides. Los linfocitos activados salen de los ganglios por los vasos linfáticos eferentes y llegan de nuevo a la sangre, llevando su influencia protectora a todos los lugares del organismo. Los linfocitos desembocan nuevamente a los ganglios linfáticos, donde el ciclo se repite.

Anteriormente comentamos el origen de la memoria adaptativa; pues bien, ésta se debe a la inmunidad adaptativa que es la resistencia a una enfermedad recidivante. Guardamos esa memoria porque el organismo conserva linfocitos que respondieron ante el episodio anterior y pueden ahora reactivarse prestamente en la invasión del mismo Ag. o determinante antigénico. Por contra, el sistema innato no distingue entre un Ag. u otro; en consecuencia, no protege más ni menos después de la exposición inicial. Pero estos beneficios se ven depreciados por un doble inconveniente: se tardan más de cinco días en desarrollar una respuesta de anticuerpos, pues las células B han de proliferar y especializarse antes de sintetizar Ac.'s Y, por otro lado, cualquier macromolécula puede ser reconocida por un Ac.; por lo que en ocasiones, el sistema inmunitario adaptativo sintetiza Ac. contra las propias células del organismo. Estos anticuerpos activan el complemento con tal eficacia, que el sistema que le impide atacar a las células propias se siente impotente, conduciendo a enfermedad autoinmune. El ataque de "lo propio", suele evitarse mediante la tolerancia, un proceso que elimina las células autorreactivas. 


\subsection{Factores que conducen a enfermedad autoinmune}

Los organismos disponen de diversos mecanismos para distinguirse los unos de los otros. No obstante, el cuerpo humano ha desarrollado uno de los más elaborados mecanismos de los invasores y el propio cuerpo. Las células del sistema inmunitario han de aprender a tolerar cada tejido, cada célula, incluso cada proteína del cuerpo sin dejar de repeler a los agentes extraños.

Recientemente se ha podido averiguar qué impide a los linfocitos el ataque a su huésped natural: Durante su estadio inmaduro, estas células inmunitarias serán eliminadas por destrucción o inactivación en el timo o la médula ósea. Si se hallan en estadios maduros, sufrirán el mismo destino si responde a algún elemento propio del organismo. En ello median mensajeros químicos que suelen ser dos señales: una la producida por el anclaje del Ag. con el receptor de la célula $\mathrm{T}$, y la otra que acostumbra ser la secreción y unión a una proteína con el CD28, en líneas generales. Si un LT queda expuesto ante una proteína propia y presentada por una célula no estimuladora, la célula T morirá o se inactivará. Esta eliminación recibe el nombre de teoría de la delección clonal.

Los mecanismos de tolerancia que afectan a las células B son muy semejantes a los de las células T inmaduras. Las células B inmaduras mueren o se inactivan cuando sus receptores se unen a algo. Se desconoce por el momento si la tolerancia pueden imponerse a las células B maduras, como sucede con las T maduras.

Si estos mecanismos fallan y los linfocitos reaccionan frente a "lo propio" constituyen una causa probable de enfermedad autoinmunitaria, éstos "autoantígenos" serán los responsables de los cuadros clínicos asociados. 
El fenómeno por el cual el sistema inmunitario aprende a tolerar las células del propio organismo es un proceso de aprendizaje a lo largo del desarrollo del individuo, dada la falta de control absoluto que el organismo puede hacer del proceso de síntesis de los receptores, pues en dicha síntesis intervienen combinaciones fortuitas de fragmentos génicos especializados, con lo cual no puede venir determinado genéticamente. Por otro lado, durante el desarrollo embrionario las células tolerarán la exposición a células que no proceden del propio organismo, hecho constatable, pues las células inmunitarias quedan expuestas a la mayoría de productos de uno mismo durante su desarrollo en el timo, en el caso de los LT, o porque son llevadas hasta allí por células viajeras desde otros lugares del cuerpo, el riñón, por ejemplo. Las células $\mathrm{T}$ jóvenes cuyos receptores se unen a productos propios del organismo mueren o se inactivan. Como algunos productos de éste nunca llegan al timo, habrá células autorreactivas que alcancen la madurez. Esta explicación establece la base de la influencia de los factores ambientales externos en la predisposición a la enfermedad autoinmune y alergias; lo primero por pérdida de la capacidad de diferenciar lo propio de lo extraño sucediéndose reactividad hacia los propios tejidos y células del sujeto; y lo segundo, alergias, por un sistema inmunitario hiperreactivo.

Esta teoría se complementó con la hipótesis de que la tolerancia del sistema inmunitario ante "lo propio", se debe a la existencia de unas células supresoras (una clase de linfocitos) que son capaces de evitar la maduración de células T y B autorreactivas. En última instancia, es especialmente relevante la contribución de los "péptidos señal" situados en el MHC, presentes en todas las células del organismo.

Otra cuestión a tener en cuenta es la influencia de la situación de estrés, por patología asociada porque afecte al hipotálamo o la pituitaria que pueden secretar sustancias que propicien la inflamación, estimulando la liberación de citocinas que viajan hasta estas dos glándulas cerebrales y hacen que éstas secreten factor liberador de 
corticotropina -CRH-, que ejerce dos efectos contrapuestos: por un lado aumenta la actividad de las células inmunitarias en el lugar donde se produce la inflamación y, al mismo tiempo actúa sobre las glándulas adrenales estimulando la producción de glucocorticoides que detienen la inflamación y cuyos mecanismos escapan a la atención de este epígrafe.

En las situaciones de estrés, se han documentado muchos casos que explican la relación entre ansiedad y el agravamiento de las enfermedades autoinmunes.

Por otro lado, existe incertidumbre en cuanto a las remisiones y recaídas de estas enfermedades: las remisiones pueden durar meses o años; la enfermedad, progresar más despacio o más deprisa, y las complicaciones, aparecer o no. La probabilidad de desarrollar otra enfermedad autoinmunitaria aumenta en las personas que ya padecen una.

Otro componente de reciente descubrimiento es la vinculación del Sistema Nervioso en la inmunidad: los nervios pueden liberar ciertos neuropéptidos en la piel, lo que afecta a la intensidad de la respuesta inmunitaria local.

Todos los casos anteriores ilustran el profundo entusiasmo en el terreno inmunológico por establecer mecanismos frente a patologías de alta incidencia actual en el campo de la autoinmunidad:

Enfermedad de Addison (glándulas adrenales), Anemia hemolítica de tipo inmunitario (proteínas de la membrana de los eritrocitos), Enfermedad de Crohn (intestino delgado), enfermedad de Graves (tiroides), Diabetes mellitus insulinoindependiente (células b del páncreas), Esclerosis múltiple (cerebro y médula espinal), Miastenia gravis (placa motora), Anemia perniciosa (células parietales 
gástricas), Psoriasis (piel), Lupus eritematoso (DNA, plaquetas y otros tejidos), Escleroderma (corazón, pulmón, intestino riñón), y otras enfermedades relacionadas.

Se está viendo que la autoinmunidad se está extendiendo de una manera sorprendente. Además, complica muchas enfermedades cuya causa primaria no tiene nada que ver con la respuesta inmunitaria.

Antes de comenzar a abordar el apartado que nos resta, analizaremos la eficacia parcial de los tratamientos de las enfermedades autoinmunitarias, los cuales sientan la base de la profundización en los de las Alergias, el otro gran compromiso en la investigación inmunológica actual.

Los tratamientos con el Ac. implicado en la reacción autoinmune sustentan la base de evitar la unión y formación del complejo Ag.-Ac., o se evita la unión a sus receptores. Mediante la administración de la proteína básica comprometida en la patología por vía oral, el organismo la aceptará y provocará que las células T secreten citocinas, como el TGF-Beta y así se contrarrestan los efectos perjudiciales de la administración del IFN-gamma y del TNF. No obstante, los tratamientos deben ser específicos y aun se precisa mayor compleción de los mecanismos inmunitarios. Cuando se disponga de terapias selectivas, el esfuerzo se centrará en la reparación de los tejidos dañados.

El tratamiento perfecto contra la autoinmunidad sería aquel que silenciase o eliminase sólo la parte autodestructiva del sistema inmunitario, dejando intacto el resto, para que pudiese combatir eficazmente las infecciones.

\subsection{Reacciones de hipersensibilidad. Alergias}

Anteriormente se ha descrito una de las cuatro grandes categorías generales de transtornos del Sistema Inmunitario, éstas son: 
1. Reacciones de hipersensibilidad, que constituyen los mecanismos de lesión inmunitaria y al que se refieren distintas patologías, entre las cuales se hallan determinadas reacciones provocadas por sensibilización a alimentos o componentes nutricionales de los mismos, alergias, y que se tratarán seguidamente a esta clasificación.

2. Enfermedades autoinmunitarias, debidas a reacciones inmunitarias frente a los propios tejidos del organismo, las cuales han sido tratadas previamente.

3. Síndromes de deficiencia inmunitaria, de las cuales solo referiremos que son consecuencia de defectos relativamente bien definidos de algunos de los componentes de la respuesta inmunitaria normal, linfocitos, macrófagos, célula madre pluripotencial o el complemento y que pueden ser de origen genético o adquiridos.

4. Amiloidosis: se trata de una enfermedad sistémica y es un transtorno mal comprendido que tiene asociación inmunitaria: se trata de una enfermedad sistémica. El amiloide es una sustancia proteinácea patológica que se deposita entre las células de distintos tejidos y órganos del cuerpo en una amplia variedad de situaciones clínicas. Puede presentarse como una alteración anatómica insospechada que no produce alteraciones clínicas, o como una enfermedad capaz de causar la muerte.

En cualquier caso, son extremadamente infrecuentes, al contrario que las reacciones de hipersensibilidad, las cuales son cada vez más frecuentes debido al entorno rebosante de sustancias capaces de provocar dichas respuestas inmunitarias.

Hipersensibilidad 
El contacto con el Ag. no solo produce una respuesta inmunitaria protectora, sino que también puede causar reacciones dañinas para los tejidos. Los antígenos exógenos se encuentran en el polvo, los pólenes, los alimentos, los fármacos, los agentes microbianos, los productos químicos y numerosos hemoderivados empleados en la práctica clínica. También pueden ocurrir a causa de Ag. intrínsecos del organismo, llamados Ag. endógenos. Esta diferencia es importante debido a que permite establecer el origen ambiental de los exógenos, cuestión que podría evitarse, al menos en teoría. Las respuestas inmunitarias causadas por tales antígenos exógenos o endógenos adoptan distintas formas, que oscilan desde molestias triviales, tales como prurito, hasta procesos que pueden provocar la muerte, como el asma bronquial. Las diferentes respuestas reciben el nombre de reacciones de hipersensibilidad.

Los transtornos de hipersensibilidad se clasifican habitualmente según el mecanismo inmunitario que media en ellas, y que resulta particularmente útil para el diagnóstico, pues con este enfoque, se puede comprender el curso clínico y, en última instancia, la lesión del tejido y la enfermedad.

\section{Hipersensibilidad de tipo I}

La respuesta inmunitaria libera sustancias vasoactivas y espasmogénicas que actúan sobre los vasos y el músculo liso, modificando su función. Más tarde incidiremos sobre este particular, pues es la Alergia un tipo de hipersensibilidad inmediata de tipo I o anafiláctica.

\section{Hipersensibilidad de tipo II}


Los anticuerpos humorales participan directamente en la lesión de las células, predisponiéndolas a sufrir lisis o fagocitosis. Está mediada, pues, por Ac. dirigidos contra los Ag's presentes en la superficie de las células u otros componentes tisulares.

Se producen tres mecanismos diferentes dependientes de los Ac.'s involucrados en este tipo de reacción.

1. Reacciones dependientes del complemento, por lisis directa: mediando el complejo de ataque a membrana, u opsonización: sensibilización a la fagocitosis por efecto de la fijación del Ac. o del fragmento C3b a la superficie celular.

Un ejemplo clínico lo constituye la anemia hemolítica autoinmunitaria o los casos de algunas reacciones medicamentosas.

2. Citotoxicidad mediada por células dependientes de anticuerpos (CTDA); en ella, hay intervención activa leucocitaria y median monocitos, neutrófilos, eosinófilos y células NK en la patología. Los Ac. involucrados son de clase Ig G. Ocurre la lisis celular sin fagocitosis.

Ejemplos clínicos son muy diversos, pues poseen la característica común de la destrucción de objetivos cuyo gran tamaño impide su fagocitosis.

3. Disfunción celular mediada por Anticuerpos: son los casos en los Ac.'s dirigidos hacia los receptores de la superficie celular pueden modificar o alterar la función sin causar lesiones celulares ni inflamación.

La enfermedad de Graves o la miastenia grave ilustran este tipo de reacciones inmunitarias. 
3. Hipersensibilidad de tipo III (Mediada por Inmunocomplejos).

Se debe a la formación de complejos Antígeno-Anticuerpo que causan lesión tisular a consecuencia de su capacidad para activar distintos mediadores séricos, particularmente el sistema del complemento y conducen a patologías localizadas, en cuyo caso de denomina reacción de Arthus; o sistémicas, en función del alcance de los acúmulos; ambos con mecanismos diferentes no bien conocidos hoy en día. Se sabe que son causa de lesión los Ac.'s fijadores del complemento, es decir IgG, IgM y, puesto que es capaz de activar el complemento por la vía alternativa, también la Ig A.

Casos como algunas formas de glomerulonefritis o artritis, son representativos de estos transtornos.

\section{Hipersensibilidad de tipo IV (Mediada por Células).}

Este tipo de hipersensibilidad se inicia por acción de los LT específicamente sensibilizados. Comprende las clásicas reacciones de hipersensibilidad retardada iniciada por las células T CD4 y la citotoxicidad directa mediada por células T CD8.

Es el patrón de respuesta inmunitaria fundamental frente a diversos agentes microbianos intracelulares y también frente a numerosos virus, hongos, protozoos y parásitos. También lo son las denominadas dermatitis de contacto por sustancias químicas, de gran auge en la investigación toxicológica.

Del primer caso es especialmente relevante destacar que un mediador sumamente importante en la hipersensibilidad retardada es el IFN-gamma, pues es un potente activador de los macrófagos; si la activación persiste o no se detiene, conducirá a fibrosis por esta causa. También lo son, aunque en menor medida, la IL-2 y el TNF. 
En la citotoxicidad mediada por células, las células T CD8, denominadas anteriormente LTCitotóxicos, destruyen las células diana portadoras del Ag. Los LTC dirigidos contra los Ag. de histocompatibilidad de las superficies celulares, desempeñan un papel en el rechazo de los Ag.'s. También intervienen en la resistencia a las infecciones virales, pues las células T citotóxicas los complejos formados por los péptidos virales asociados a las moléculas de clase I del MHC, exponiéndose en la superficie celular para la acción de los LTC.

\subsection{Alergias. Clasificación}

La alergia es la reacción denominada Hipersensibilidad Inmediata, que se encuadra dentro del tipo I de la clasificación adoptada. La hipersensibilidad de tipo I es una respuesta inmunitaria de desarrollo rápido, que se desencadena algunos minutos después de la combinación de un Ag. con un Ac. ligado a mastocitos o basófilos en organismos previamente sensibilizados a ese Ag., también denominado alergeno o alérgeno -sustancia inductora de alergia-. Pueden adoptar la forma de un transtorno generalizado o local.

Las reacciones de hipersensibilidad local de tipo I poseen dos fases bien definidas:

La primera, la respuesta inicial, está caracterizada por vasodilatación, extravasación y, dependiendo de su localización, contracción del músculo liso o secreción glandular. Estos cambios suelen ponerse de manifiesto de 5 a 30 minutos después del contacto con el alergeno y tienden a resolverse al cabo de unos 60 minutos. A menudo, provoca un estado de shock que, a veces, puede ser mortal. Las reacciones locales dependen de la vía de entrada del alergeno y se manifiestan como tumefacción cutánea -alergia cutánea-, secreción nasal y conjuntiva -conjuntivitis alérgica-, fiebre del heno, asma bronquial o gastroenteritis alérgica -alergia alimentaria-. 
La segunda, se denomina "reacción de fase tardía", se produce en muchos casos y aparece después de 8 a 10 horas de la exposición y dura varios días sin que medie contacto adicional con el alergeno. En esta reacción, se produce una infiltración más intensa de los tejidos por los eosinófilos, neutrófilos, basófilos y monocitos, así como destrucción celular que lesiona el epitelio de las mucosas.

Los mastocitos y sus parejas circulantes, los basófilos, denominados genéricamente como células cebadas o granulocitos, son elementos fundamentales en el desarrollo de las alergias, por ello, pasaremos a tratarlos brevemente:

Los mastocitos son células procedentes de la médula ósea que se encuentran ampliamente distribuídos por los tejidos, especialmente en los lugares donde tienden a producirse las reacciones locales de tipo I, cerca de los vasos sanguíneos y epitelios. El citoplasma posee gránulos rodeados de membrana que contienen numerosos mediadores biológicamente activos.

Los basófilos son muy parecidos a los mastocitos, solo que se no se encuentran en los tejidos, circulan por la sangre en muy escaso número y pueden verse atraídos a los focos inflamatorios.

Los mastocitos y basófilos se activan tras la formación de enlaces cruzados con los receptores Fc de Ig E de gran afinidad, además de componentes C5a y C3a del complemento que se unen a la membrana celular (llamados anafilatoxinas). También se activan por citocinas procedentes de los macrófagos, algunos fármacos como la codeína y morfina, y otros estímulos químicos como la metilina (presente en el veneno de la abeja y otros himenópteros). Estímulos físicos como el calor, el frío y la luz solar. 
En el hombre, las reacciones de tipo I están mediadas por Ac. Ig E y, como ya se comentó, constituye uno de los mecanismos efectores más importantes del sistema inmunitario. En cualquier caso, se sabe que algunas de las interacciones celulares y moleculares que constituyen la respuesta alérgica suelen coincidir en personas distintas, aunque sean diferentes los alérgenos causantes y los síntomas manifestados.

Ciertos rasgos de la alergia solo vuelven a darse cuando el sistema inmunitario intenta erradicar parásitos; lo mismo en la respuesta ante alérgenos como ante la presencia de parásitos, el cuerpo sintetiza cantidades elevadas de anticuerpos del tipo inmunoglobulina E cuya valoración sérica constituye una prueba que puede inclinar el diagnóstico hacia la existencia de patología alérgica y de lo que más tarde se expondrá.

Por el contrario, cuando el sistema inmunitario combate otros invasores, recurre a otras clases de Ac's. De cualquier modo, no existen pruebas concluyentes de las razones por las que existe la alergia, aunque se trata de justificar el desarrollo y evolución de las mismas por la elevada exposición a distintos contaminantes.

La activación de mastocitos y basófilos se suele iniciar de forma característica cuando un alergeno específico se une a moléculas de $\operatorname{IgE}$ ya unidas a su superficie, y las entrecruza. La secuencia de fenómenos que generalmente se repite en un proceso alérgico, es como sigue:

1. Producción de $\operatorname{IgE}$ por células $B$ en respuesta a la primera exposición a un alérgeno.

2. Unión de la $\operatorname{IgE}$ a receptores específicos para su Fc en la superficie de los mastocitos y de los basófilos. 
Los dos procesos anteriores constituyen la etapa de sensibilización.

3. Interacción entre el alérgeno reintroducido con la Ig E unida.

4. Se produce la activación de las células y la liberación de los mediadores, algunos de los cuales se encuentran almacenados en los gránulos citoplasmáticos de los mastocitos y basofilos, en un proceso conocido como desgranulación, en ella se liberan distintos tipos de mediadores.

\section{Sensibilización}

Aunque las manifestaciones externas de la respuesta alérgica varían, ésta siempre se pone en marcha mediante un proceso silente clínicamente denominado sensibilización.

Comienza la primera vez que un alérgeno, de ordinario una proteína, entra en el cuerpo. En las vías respiratorias, o en otros tejidos, la sustancia que induce la alergia encuentra células limpiadoras o macrófagos, las cuales fagocitan y opsonizan dicha sustancia. Las interacciones que se continúan en este proceso aún se desconocen; pero se sabe que los LTH reconocen algunos de los fragmentos expuestos y se anclan en ellos. La unión estimula la secreción de IL-4 y otras moléculas que promueven la maduración de los LB en células plasmáticas secretoras de Ac's que, en principio serán Ig M, para pasar a sintetizar Ig E. Transcurren días o semanas antes de la producción de Ac's y el alérgeno que provocó su producción puede haber desaparecido entre tanto. Pero el proceso de hipersensibilidad ya ha comenzado: las moléculas de Ig E se unen por la porción Fc de las cadenas pesadas a los receptores de Ig E de células cebadas; una vez comenzada la síntesis de Ac's Ig E persiste durante meses o años; en consecuencia, los Ac's Ig E ocupan perpetuamente los receptores de $\mathrm{Ig} \mathrm{E}$ de los mastocitos y basófilos, donde están listos para actuar con 
rapidez cuando se produzca el próximo encuentro con el alergeno. Por tanto, incluso en una persona que más tarde resultará ser alérgica, el encuentro inicial no provoca síntomas, pero instruye al sistema inmunitario para que reaccione en una exposición posterior.

Activación de Mastocitos

La primera exposición inicia un estadio donde la visibilidad y significación clínica es mayor. Segundos después de que un alergeno se encuentre en tejidos humanos se une a Ac. Ig E en los mastocitos. Cuando afecta al menos a dos moléculas de Ig E, forma un puente entre ellas. Este entrecruzamiento acerca entre si los correspondientes receptores de Ig E. Tal agregación de receptores activa la célula, es decir, la induce a la liberación de potentes sustancias químicas por fusión de sus gránulos con la membrana de la célula. Estas sustancias son los mediadores primarios: aminas biógenas, que fundamentalmente son la histamina y la adenosina; mediadores quimiotácticos, enzimas proteasas e hidrolasas ácidas, y proteoglicanos. Dichos mediadores directa o indirectamente provocan los síntomas alérgicos; entre ellos, cabe destacar la histamina como el principal desencadenante de los síntomas.

La histamina, descrita en 1.911 es quizás de entre estos mediadores preformados, el que peores consecuencias tiene: puede estimular la producción de moco del epitelio con lo que contribuye a la congestión de las vías respiratorias, proceso denominado rinitis alérgica-, causar la constricción del músculo liso bronquial e intestinal, y dilatar los vasos sanguíneos y aumentar su permeabilidad, con lo que el fluído invade los tejidos. Estos cambios vasculares originan habón y eritema (enrojecimiento e hinchazón) y, si los cambios se extienden, una situación mortal de shock hipotenso -anafilaxia sistémica-. 
Entre las sustancias liberadas, los mastocitos también producen con posterioridad a la unión de la Ig E mediadores secundarios, que son metabolitos activos del ácido araquidónico: leucotrienos, muy importantes en la patogenia de la hipersensibilidad de tipo I, prostaglandinas y factor activador de plaquetas -PAF-. Al igual que la histamina, ambos lípidos provocan constricción bronquial y dilatación vascular y, lo que agrava dichas consideraciones, sus efectos duran más tiempo. También se producen polipéptidos tales como diversas citocinas, que activan otras células del sistema inmunitario, como ya se explicó.

\section{Actividad Inmunitaria Prolongada}

La alergia es parte de una respuesta mayor que conduce a la formación de infiltrados inflamatorios ricos en eosinófilos en un proceso conocido como reacción de fase tardía.

En la mayoría de las ocasiones la reacción alérgica progresa hasta un tercer estadío que, a menudo se convierte en crónico. Se supone que los mastocitos activados estimulan el paso de otras células inmunitarias de la circulación sanguínea a los tejidos. Entre esas células se incluyen los basófilos y eosinófilos que, al igual que los mastocitos, son células cebadas o granulocitos. También se localizan los LT y los monocitos. La presencia de un elevado número de basófilos y eosinófilos en una lesión inflamatoria constituye una característica común de las alergias; pues en lugares de infección bacteriana abundan los neutrófilos y otros leucocitos.

Las células cebadas pueden segregar mediadores que pueden prolongar y exacerbar los síntomas inmediatos y producir lesiones en el tejido local. Por ejemplo, los basófilos activados de esta manera secretan muchos mediadores primarios y secundarios. Los eosinófilos liberan toxinas; una de ellas denominada como proteína básica puede dañar las células del epitelio al cual se expuso el alergeno. 
Establecidas las consideraciones básicas de estos fenómenos de hipersensibilidad de tipo I, se tratarán ahora algunos procesos generales mediados por la Ig E cuya significación clínica se ha dado en llamar ANAFILAXIS.

\section{Anafilaxis}

En el hombre, la anafilaxia puede producirse de cualquiera de los modos descritos hasta ahora, todos ellos debidos a la exposición a proteínas heterólogas, alergenos, que constituyen la base de la reacción alérgica.

La gravedad del transtorno depende del grado de sensibilización; sin embargo, la dosis de alergeno capaz de provocar el shock puede ser sumamente pequeña como ocurre con las mínimas cantidades utilizadas en las pruebas cutáneas habituales empleadas para el diagnóstico de las distintas formas de alergia.

Tras la exposición, las actividades celulares de la fase aguda se manifiestan en estornudos, congestión o pitos y disnea, si la vía de exposición fue inhalativa; o habón y eritema mantenidos, si la vía de absorción fue epitelial; o irritación gástrica, eritema, vómitos, cólicos abdominales, espasmos si la vía fue enteral, como es el caso de las Alergias Alimentarias; hecho que se expondrá a continuación de manera más detallada.

Los síntomas descritos desaparecen al cabo de una hora, pero vuelven horas más tarde, en paralelo a la invasión del epitelio por las células circulantes en la fase tardía. Otros síntomas se verán potenciados llegando incluso a la muerte del individuo por obstrucción laríngea, colapso circulatorio o insuficiencia respiratoria. Lo más común es que tras un ataque agudo de alergia no se experimentarán los transtornos de la fase tardía, excepto si un individuo sensibilizado es expuesto sucesivas veces a los 
alergenos; en cuyo caso puede acabar padeciendo una inflamación persistente de fase tardía y síntomas continuos o fácilmente provocados.

Naturaleza del Antígeno: Alérgeno

Como ya se ha comentado, los antígenos que desencadenan la reacción de hipersensibilidad inmediata se denominan alergenos o alérgenos, y son sustancias de naturaleza proteica; tanto proteínas como sustancias químicas unidas a proteínas. No se sabe la causa de que algunos Ag's producen fuertes respuestas alérgicas, mientras que otros, que pueden penetrar por la misma vía de administración, no son alérgicos. La alergenicidad puede residir en el propio Ag. Algunos fármacos, como la penicilina, desencadenan de forma característica fuertes reacciones mediadas por Ig E. Se cree que éstos fármacos unidos a proteínas propias, forman conjugados que actúan como "neoantígenos".

Las personas muy sensibilizadas, es decir, con alergias graves, se caracterizan por tener concentraciones elevadas de Ig E sérica, lo cual se considera, a efectos de diagnóstico no concluyente que la $\mathrm{Ig}$ E total es mayor que 1.000 u. Además, tienen más receptores de alta afinidad para el Fc de Ig E en los mastocitos y una mayor proporción de los mismos ocupados por Ig E que las personas no alérgicas. Los niveles de $\mathrm{Ig}$ E en sujetos alérgicos son mucho menores que los de otras clases de $\mathrm{Ac}^{\prime}$ s, pero llegan a ser miles de veces mayores que los de las personas no alérgicas.

Las formas más comunes de enfermedad alérgica son la rinitis alérgica, el asma bronquial y la dermatitis atópica. Las características clínicas y patológicas de las reacciones alérgicas varían con la localización anatómica debido a una serie de factores:

La naturaleza y el punto de contacto con el alergeno. 
La concentración de mastocitos en varios órganos diana.

El fenotipo del mastocito local.

La sensibilidad de los órganos diana a los mediadores mastocitarios y granulocíticos.

Finalmente, hay que tener en cuenta que hay ciertos tipos de Ag's, incluídos los pólenes de las plantas, los ácaros del polvo y algunos fármacos y alimentos que producen de forma característica reacciones alérgicas.

\section{El alimento como tóxico potencial}

\subsection{Relación del alérgeno en la generación de autotoxicidad}

Las reacciones frente a los alimentos se reconocen cuando se presentan síntomas graves de comienzo rápido y dramático; por ejemplo, cuando se produce una casi inmediata situación de anafilaxia, como reacción cutánea generalizada con vómitos y descenso brusco de la tensión arterial o hinchazón de los labios y la boca.

De entre las respuestas inmunes provocadas por alimentos se ha demostrado la implicación directa de alimentos en reacciones de hipersensibilidad tipo I, como es el caso de la nuez y el huevo, en cuyo caso la patología cursa con los síntomas ya descritos y específicamente en las mucosas del tracto gástrico e intestinal, sin excluir la posible reacción de anafilaxia sistémica de comienzo repentino y, a veces, dramático.

En las reacciones de tipo II aún no se ha demostrado una lesión directa producida por Ac. en las reacciones a los alimentos, aunque se ha sugerido que los Ac. Ig G frente a la gliadina del trigo que aparece en la enfermedad celiaca pueden producir lesiones tisulares directas mediante reacción cruzada con la reticulina de las células del intestino. Sin embargo, no hay pruebas concluyentes de un efecto directo de la 
gliadina sobre los tejidos. Aun así, los datos experimentales apuntan a que las enfermedades asociadas con un incremento de la permeabilidad de la mucosa intestinal, permiten el desarrollo de una respuesta de Ac. IgG frente a las proteínas alimentarias capaces de atravesar la mucosa, pero esto no provoca síntomas ni enfermedades.

Para el caso de las reacciones de tipo III, no hay conexión clara de manifestaciones alimentarias de este tipo. Considerar que, algunas patologías renales o artríticas pueden favorecer la aparición de reacciones mediadas por inmunocomplejos frente a determinados alimentos, como es el caso de la proteína de leche de vaca.

Los datos existentes en el caso de la hipersensibilidad de tipo IV en las que participan LT, evidencian claramente el papel fundamental en las reacciones de intolerancia a los alimentos: característico en la intolerancia al gluten de los enfermos celiacos. Microscópicamente, se observa la formación de vesículas bajo las células, y una separación de la membrana basal, que también conducen a la activación de los mastocitos y de las células B y a lesiones de las vellosidades intestinales y epitelio mucoso.

En otro sentido, numerosos alimentos de consumo relativamente frecuente contienen sustancias tóxicas naturales, tal es el caso de los glicoalcaloides de la patata o los glicósidos cianogenéticos de algunas judías y raíz de mandioca. Se engloban también en este apartado las diferentes especias: canela, pimienta negra, cúrcuma, etc. Aunque debemos señalar que, en la mayoría de los casos, sólo son tóxicas si se ingieren en cantidades elevadas; además de que durante el cocinado desaparece su toxicidad o disminuye a límites mucho más tolerables.

Del mismo modo, hay regiones en las cuales no hay un buen almacenamiento o manipulación de los alimentos, lo que ocasiona que contengan toxinas procedentes 
de la contaminación fúngica o bacteriana o de cambios degenerativos. Existen numerosas otras vías por las que los alimentos pueden producir efectos tóxicos, como es el caso de las reacciones frente a los mariscos, los cuales se contaminan con las toxinas de los flagelados que pueden llegar a consumir.

Finalmente, no todas las reacciones a los alimentos son provocados por la ingestión oral: los pacientes asmáticos que inhalan metabisulfito del vino o de alimentos conservados, pueden desarrollar asma, urticaria o eccema en cuestión de minutos, no por un mecanismo de hipersensibilidad directo sino, indirectamente por la irritación de la mucosa bronquial o el epitelio.

Intolerancias y alergias

Llegados a este punto, se hace necesario definir y caracterizar las diferentes clases de reacción frente a alimentos:

La intolerancia a los alimentos es una reacción reproducible, adversa a un alimento específico o a un ingrediente alimenticio que no ofrece bases psicológicas y que ocurre aun cuando el alimento es ingerido en una forma en que es imposible su identificación.

Una alergia alimentaria es una forma de intolerancia a los alimentos en la que es evidente una reacción inmunológica anómala a los mismos y que se rige por las características comentadas anteriormente.

La intolerancia a los alimentos puede generarse a través de otros mecanismos distintos a los referidos para las alergias. Puesto que el proceso digestivo depende de la acción de enzimas capaces de degradar los alimentos, la intolerancia puede deberse a un fallo de estos procesos, en virtud de deficiencias enzimáticas, por 
ejemplo la deficiencia de lactasa. Entre las causas de intolerancia se encuentran también los efectos farmacológicos, similares a los de los medicamentos, como por ejemplo los debidos a la cafeína o metil-xantinas; los efectos tóxicos causados por irritación directa, como el caso de la irritación esofágica producida por reflujo gastroesofágico.

Hay un tercer componente a destacar: la aversión a un alimento, que ofrece dos modalidades; a saber: el rechazo psicológico, es decir, existencia de motivos psicológicos para evitar el consumo de un determinado alimento; y la intolerancia psicológica, que es una reacción física desagradable causada por emociones asociadas a su consumo, más que por el alimento en sí.

En tales casos, los síntomas se presentan siempre que el alimento se reconoce, pero no cuando éste se suministra en una forma que no permite su identificación. En cualquier caso, los síntomas siempre son indirectamente provocados.

Por último, una cuarta categoría la constituyen los tóxicos alimentarios que engloba a los tóxicos naturales, los contaminantes biológicos constituyendo las bien conocidas toxiinfecciones alimentarias; los constituyentes inorgánicos del agua y el suelo, los aditivos alimentarios aunque se consideran generalmente reconocidas como seguras (sustancias GRAS), se relacionan ampliamente como cancerígenos o aparición de fenómenos de hipersensibilidad; por ello los estudios se actualizan constantemente ante el eventual riesgo. Otros tóxicos que pueden estar presentes en los alimentos son los tóxicos formados durante la manipulación o almacenado del alimento, bien por concurso de agentes físicos -calor, luz-, o por acción catalítica de materiales presentes o en contacto con él; también los carcinógenos naturales y las interacciones de alimentos con diversas sustancias. 


\subsection{Descripción del alérgeno}

La mayor parte de los alimentos que pueden actuar como antígenos y provocar una reacción inmunológica son proteínas o glicoproteínas. Numerosas proteínas, entre ellas las del bacalao han sido aisladas, cristalizadas y detalladamente analizadas. Las proteínas más reactivas de la leche o el huevo tienen pesos moleculares de entre 10.000 y 50.000, pero no hay ninguna regla que limite su tamaño o su estructura molecular. La intensidad de la reacción despertada pueden depender, en parte de su semejanza o su diferencia con las proteínas humanas; una de las proteínas más reactivas para los lactantes alérgicos a la leche de vaca es la Beta-lactoglobulina, que no es la más abundante, pero que tiene la particularidad de ser el único tipo de proteína de la leche de vaca que no se encuentra en la leche humana, como veremos más adelante.

Una vez desarrollada una reacción alérgica a una proteína, pueden presentarse reacciones cruzadas con proteínas similares de otras fuentes, por ejemplo entre la albúmina de la clara del huevo de gallina, las proteínas de la yema y las de los huevos de otras aves. La resistencia de una proteína al tratamiento culinario puede afectar también a su potencial antigénico. Las proteínas de la leche o del huevo se desnaturalizan por la cocción y, después de cocinadas, a veces son toleradas por las personas alérgicas. Las proteínas del cacahuete son relativamente termoestables y pueden provocar efectos idénticos tanto si están crudos como si han sido tostados. Más adelante, se tratarán especialmente los antígenos alimentarios.

Por otra parte, existen numerosas reacciones clínicas a los alimentos que se deben al "mimetismo" con ciertos componentes biológicamente activos y que desencadenan la sintomatología de la reacción alérgica pero que no tienen una causa alérgica; son las denominadas Reacciones Pseudoalérgicas. Se conoce aun no mucho de los mecanismos que conducen a esta respuesta, pero se sabe que el efecto químico de las 
aminas biológicamente activas, las aminas biógenas, constituyen el ejemplo por excelencia. En este caso, hay un hecho trascendental: se ha calculado que menos de un 3\% de los pacientes con erupciones cutáneas recurrentes (urticaria crónica) y síntomas abdominales intermitentes, sufren una auténtica alergia a los alimentos. Las reacciones no alérgicas a los alimentos dan cuenta de un $40 \%$ de los casos, que es un hecho muy significativo, pues revela que las reacciones pseudoalérgicas a los alimentos son mucho más comunes que las verdaderas alergias alimentarias.

La frecuencia de las reacciones a diferentes alimentos varía con el tipo de dieta en las distintas partes del mundo. La leche, los huevos, el trigo y el pescado son los alimentos que más frecuentemente provocan intolerancia, también alergia, especialmente en niños. Puede haber incluso una sensibilización cruzada, como el caso de pacientes que sufren fiebre del heno provocada por el polen de abedul plateado y frecuentemente alérgicos a las frutas blandas de varias especies de árboles, o a los productos manufacturados que contienen harina de soja como ingrediente minoritario. Igualmente, la alergia a la goma de látex puede ir fácilmente acompañada de fenómenos alérgicos a la fruta, especialmente a plátanos y castañas.

Los alimentos que con mayor frecuencia provocan reacciones de intolerancia inespecíficas, se recogen en la tabla siguiente:

Leche.

Huevos.

Trigo, cereales.

Levadura.

Pescado, mariscos. 
Nueces, cacahuetes.

Cerdo, carne ablandada.

Chocolate.

Frutos cítricos.

Arroz.

Garbanzos.

Café, té.

Conservantes.

Otros aditivos.

\subsection{Epidemiología. Efectos e incidencias en la población}

Es muy difícil conocer la incidencia y distribución de las intolerancia a los alimentos en la población en general, dado que no existen procedimientos diagnósticos prácticos aplicables en una encuesta de población. Los cuestionarios carecen de valor real a menos que puedan tenerse en cuenta los errores de autodiagnóstico de personas que creen que se encuentran afectadas. Además, los síntomas que pueden provocar los alimentos y los aditivos alimentarios varían, siendo el aspecto a pretender el ensayo clínico controlado, en el que suministra al paciente en diferentes momentos el alimento sospechoso y otra sustancia indistinguible del mismo y se 
observan las consecuencias. De todos modos las pruebas para establecer la validez de las pruebas diagnósticas son difíciles de realizar en la escala necesaria para un estudio de población. Por todo lo anterior, los epidemiólogos se ven obligados a utilizar datos diagnósticos poco fiables, con lo cual las conclusiones que de esos estudios deriven, son limitadas.

Las respuestas recogidas mediante cuestionarios sugieren que entre el 4,5\% y el 33\% de la población, se considera a sí misma proclive a las reacciones de alergia o intolerancia a algún alimento. Ensayos más cuidadosos tras el consumo del alimento en cuestión, revelan unas cifras sensiblemente inferiores: el grado de infraestimación suele ser bastante considerable, según estudios recientes, en tal caso, la dependencia de que existan elementos diagnósticos precisos es indicativo de un buen estudio poblacional; ello ocurre en las patologías que suelen ser suficientemente graves como para exigir el estudio minucioso en un centro hospitalario, como la Intolerancia al gluten o la intolerancia a la lactosa.

El primer caso de intolerancia a un alimento en un niño, se detectó en 1.905, como consecuencia de una reacción anafiláctica producida por la leche de vaca. Este hecho estableció las bases de un conocimiento más profundo de las alergias a los alimentos en el hombre. El efecto que causó fue la instauración de dietas inadecuadas por los padres, con los consiguientes problemas nutricionales para el niño.

Casi la mitad de los casos de alergia alimentaria en la infancia se dan durante el primer año de edad y el 70\% de los casos ocurren antes de los dos años. La leche de vaca es, con gran diferencia, la más común de las causas de reacción a los alimentos en la infancia. La incidencia estimada de diarrea por esta causa varía ampliamente, pero es muy probable que no afecte a más del 1\% - 2\% de la población occidental. A medida que la dieta de los niños se hace más variada, empiezan a aparecer 
problemas causados por otros alimentos, quedando patente, en este orden, los huevos, el pescado, la soja y el trigo.

Se ha publicado que los niños con sensibilización tipo Ig E temprana a la leche de vaca, tienen una probabilidad del 38\% de desarrollar alergias a otros alimentos especialmente huevos- antes de los 3 años, y un 40\% de probabilidad de desarrollar rinitis alérgica o asma.

Alrededor del 10\% de la población sufre alergias frente a alergenos exógenos, con las consiguientes reacciones anafilácticas locales. Entre estos alergenos destacan los pólenes, el epitelio de animales, el polvo casero, el pescado y otros.

La respuesta infantil normal a un antígeno alimentario al que se enfrenta por primera vez es la de tolerancia y los repetidos encuentros con el Ag. desencadenarán una respuesta por lo general, también tolerante. Como ya se ha descrito, el desarrollo de la alergia a algún alimento o componente estructural del mismo, es considerado como un fallo en el mecanismo de tolerancia normal. La sensibilidad a un alergeno alimentario puede durar unos años, como es el caso de la intolerancia a la proteína de la leche de vaca; o puede durar toda la vida, como por ejemplo, la enfermedad celíaca en la mayoría de los casos; aunque la cronicidad tiende a disminuir la gravedad.

\subsection{El factor idiosincrásico y la predisposición genética}

Las reacciones que producen las alergias inmediatas pueden ser dramáticas pero representan solo una minoría de las reacciones adversas a los alimentos. En el síndrome alérgico oral, en el que los labios, las mejillas, la lengua o la garganta, se hinchan o duelen minutos después del contacto con un alimento específico, las pruebas para detectar anticuerpos IgE han resultado positivas en la mayoría de los casos. Reacciones similares pueden afectar a la piel, los pulmones o el tracto 
gastrointestinal. Los alimentos implicados son extraordinariamente ricos en proteínas, como los huevos, la leche de vaca, el pescado, la soja o las nueces, pero también se pueden dar reacciones de este tipo frente a especias como la mostaza o la pimienta, y hortalizas, como el apio.

Existe una gran variedad de factores predisponientes que pueden contribuir a la respuesta clínica: en individuos que carecen de Ig A secretora, es más fácil que se presenten reacciones alérgicas; aunque no se han dilucidado claramente los mecanismos, parece ser que la deficiencia de IgA es suplida en las barreras mucosas por Ac. IgE. Pero hablar de predisposición supone una interacción estrecha entre las distintas causas que subyacen a un determinado individuo: estos factores pueden ser ambientales o genéticos.

A menudo, en las mismas familias, se produce la síntesis de cantidades elevadas de IgE y la alergia asociada. Aunque el patrón de herencia completo probablemente es multigénico, estudios familiares han demostrado que hay una clara transmisión autosómica de la alergia. Sin embargo, el órgano diana de las enfermedades alérgicas es variable. De esta forma la rinitis alérgica, el asma y el eccema pueden presentarse en grados variables a los diferentes miembros de una misma familia. Todos ellos van a mostrar una elevada concentración plasmática de IgE. También se hereda la capacidad de sintetizar Ac. IgE específicos frente a ciertos Ag., como el polen; y esto puede estar unido a alelos particulares de clase II del MHC.

Hoy en día se puede decir que si los dos padres son alérgicos, un hijo de ellos tiene una probabilidad del orden del 60\% - 70\% de ser alérgico; en cambio, si solo uno de ellos lo es, la proporción estimada desciende hasta un 30\%. Hay que tener en cuenta, además, la amplia variabilidad de casos; pues existen casos de padres alérgicos con gran progenie y ninguno de los hijos es alérgico. 
La conclusión a la que se ha de llegar es, inevitablemente, una herencia que es una predisposición, y la aparición de la enfermedad dependerá de si el sujeto se expone a algunos de los factores que puedan desencadenar el proceso. La base de esta predisposición genética no resulta clara. No obstante, en condiciones normales la alergia puede aparecer a cualquier edad, pero se da en mayor proporción de casos a los 30 - 40 años. También está aumentando mucho la incidencia de las ciudades y cada vez más en niños, por los contaminantes ambientales. La hipótesis sostiene que el cuerpo desarrolló en su origen la respuesta alérgica para hacer frente a los parásitos, que es la otra respuesta donde es muy relevante la participación de la IgE. Las personas capacitadas por su dotación genética para organizar un ataque inmunitario eficaz contra esos organismos sobrevivirían mejor que quienes carecieran de tal mecanismo de defensa. Con la mayor descendencia que habrían tenido, se habría asegurado la transmisión de dicha capacidad y así se extendería entre la población humana el sistema de defensa contra los parásitos. En los grandes núcleos urbanos, la población no suele estar expuesta a estos organismos y el sistema inmunitario reaccionará ante otras sustancias: los alérgenos.

Como respaldo a esta hipótesis, los epidemiólogos han observado que la alergia es menos común en las naciones en vías de desarrollo que en las industrializadas, donde las medidas de salud pública han eliminado en su mayor parte la exposición a parásitos.

Por otra parte, hemos de mencionar diferentes estudios llevados a cabo en sujetos susceptibles psicológicamente. Dichos estudios sustentan la relación recíproca entre enfermedades alimentarias de diversa índole y el factor psicológico o psíquico:

Las relaciones entre problemas psicológicos y actitudes frente a los alimentos, han sido bien definidas. Si se acepta que los cambios mentales pueden acompañar a la enteropatía provocada por el gluten y que la alergia a los alimentos en los niños 
puede ir seguida de un cambio en el comportamiento, parece razonable estudiar los posibles efectos sobre la salud psiquiátrica de los adultos provocados por la alergia a los alimentos. Se observó que, en algunos casos, la enfermedad obedecía a causas psicológicas, no existiendo indicios de ningún género de hipersensibilidad a alimentos. Fue también sorprendente la prevalencia de síntomas neuróticos comunes en estos pacientes. Es posible que los niños respondan de un modo diferente, pero no se ha demostrado que la alergia en los adultos provoque enfermedades psiquiátricas, aunque deben observarse cuidadosamente aquellos casos en los que se afirma que lo provoca, siguiendo pautas muy controladas y elementos de diagnosis muy cuidadosos.

Se han observado otras asociaciones entre reacciones a los alimentos y cambios mentales. En los niños con enfermedades metabólicas congénitas, como la PKU fenilcetonuria-, la intolerancia a las proteínas alimentarias puede causar confusión mental o afectar a la función intelectual. La mayor parte de estas condiciones son raras, pero cuando ocurre, la ingestión del alimento puede ir seguida de malestar general, inquietud e irritabilidad. La posibilidad de que los problemas de comportamiento puedan ser provocados por intolerancia a los alimentos o a los aditivos alimentarios no puede descartarse sin una adecuada consideración de la evidencia en cada caso concreto.

\section{Alergias alimentarias}

\subsection{Clasificación de los principales alérgenos}

A lo largo de los últimos años una serie de desastres tóxicos y alimentarios en general, han motivado quizás el interés por la toxicidad de los alimentos y enfermedades derivados de ellos. La presencia de poluantes ambientales y contaminantes de diversa constitución, como el uso de aditivos alimentarios y consecuente fijación de sus máximas ingestas admisibles en la dieta, etc. hacen 
inminente el establecimiento de un estudio sistemático y riguroso de estas sustancias tóxicas o potencialmente tóxicas de los alimentos y los alimentos mismos, dependiendo de las condiciones de su uso, preparación o manipulación en general.

Así, nace por una parte la Toxicología Alimentaria, encargada del estudio de la naturaleza, fuentes y formación de sustancias tóxicas en los alimentos, así como sus efectos nocivos, los mecanismos y manifestaciones de estos efectos y la prevención de intoxicaciones mediante el establecimiento de los límites de seguridad de estas sustancias. A este campo nos hemos referido en el epígrafe anterior en una de las clasificaciónes adoptadas.

La otra vertiente que reclama también un profundo estudio es el de la respuesta frente a determinados componentes de naturaleza proteica o lipídica que causan una alteración por sensibilización de los mecanismos de la respuesta inmunitaria o patologías que se evidencian por defectos enzimáticos o mal funcionamiento de órganos o tejidos implicados: el primer caso es ampliamente abarcado por la Alergología, una rama de la Inmunología y es este el enfoque pretendido.

Los alérgenos productores o inductores de reacción alérgica son numerosos y podemos clasificarlos dependiendo de la vía de entrada en el organismo en varios grupos:

Inhalantes

Son aquellos que penetran a través del aparato respiratorio y constituyen, sin duda, el grupo de alérgenos más importante. Los síntomas que producen se localizan preferentemente en las vías respiratorias, siendo las más características la rinitis alérgica (fiebre del heno) y el asma alérgica. Pertenecen a este grupo: 
Polen de gramíneas, árboles ...

Esporas de hongos.

Ácaros del polvo.

Epitelios, escamas o plumas de animales domésticos.

\section{Contactantes}

Penetran por vía percutánea, causando las denominadas "dermatitis por contacto", al actuar sobre la piel y mucosas. Comprenden gran variedad de alérgenos, entre ellos:

Plantas.

Gomas.

Tintes.

Metales.

Cosméticos.

Por inyección

A destacar aquellos alergenos que penetran en el organismo por inyección, tales como:

Venenos de himenópteros: abejas, avispas y otros insectos.

Vacunas

Algunos fármacos inyectables

\section{Trofoalérgenos}

Penetran por vía digestiva y pueden sensibilizar tanto al tubo digestivo como el árbol respiratorio. Dentro de este grupo se incluyen: 
Fármacos.

Alimentos.

Aditivos alimentarios.

\subsection{Pruebas diagnósticas}

En el establecimiento del diagnóstico se consideran dos grupos importantes de pruebas: un grupo que proporciona nociones o ideas sobre la posible alergia o intolerancia, es decir, pruebas no patognomónicas de la posible patología, no concluyentes pero identificativas de posibles procesos alérgicos alimentarios.

El otro gran grupo lo constituyen las pruebas de diagnóstico que llevan a la dilucidación de la patología y que constituyen el verdadero diagnóstico de la alergia.

En caso de alergias a alimentos se utilizan las primeras para valorar de modo rápido tal posibilidad pero poseen escaso o nulo valor, por lo que se hace evidente la validación con las que constituyen el verdadero juicio diagnóstico.

Pruebas no ortodoxas

No es difícil diagnosticar reacciones a los alimentos en pacientes que presentan un cuadro de hipersensibilidad inmediata, sobre todo si ya presentó algún síntoma anteriormente. Generalmente se presentan como habón labial, asma, reacciones cutáneas o gastrointestinales graves. En la mayoría de los pacientes el único procedimiento objetivo de confirmar una reacción clínica a un alimento es darle el alimento en cuestión por vía oral. Las pruebas para detectar la presencia de Ac's Ig E pueden presentar una medida de apoyo, pero la prueba fundamental para diagnosticar estas reacciones sigue siendo la de provocación por el alimento a "doble 
ciego" controlado con placebo para evitar el factor psíquico que predispone la aparición de los síntomas y que, en el caso de los alimentos, es relevante dicho efecto, como se mencionó anteriormente.

Entre los criterios utilizados como formas de diagnóstico que suponen identificar reacciones a los alimentos $\mathrm{u}$ otras formas de enfermedades ambientales, se observa que se basan en la amplitud de los síntomas mostrados sin ninguna base objetiva en la que sustentar dichas pruebas. Así, un paciente que haya sufrido una infección viral, presentará los mismos síntomas que la fatiga o disnea producida por un fenómeno alérgico. Asimismo ocurre con depresiones, actitudes obsesivas y cualquier hecho que relacione el alimento con problemas psicológicos, pueden ser síntomas de diversas enfermedades importantes y que solo pueden ser tratadas de forma satisfactoria si se investigan adecuadamente y se diagnostican de un modo correcto.

Cuando se sospechaba de una posible intolerancia o alergia a un alimento por parte del paciente, se le realizaban una serie de pruebas. Posteriormente se ha demostrado que dichas pruebas tienen escaso o nulo interés para el diagnóstico.

Lo primero que se practicaba sobre un paciente, para confirmar una reacción a un alimento, era administrárselo por vía oral, con el consiguiente peligro para su salud. También se le practicaba el ensayo a "doble ciego" anteriormente comentado y que consiste en administrar un alimento placebo, es decir, sin el posible alergeno en cuestión. Pero los resultados no eran nada exactos, pues se basaban en los comentarios subjetivos del paciente.

Hay una serie de pruebas que se utilizaban, entre ellas se incluyen: 
1. Prueba de pulso (Coca, 1942). Se basa en la creencia de que un paciente alérgico a un alimento ve aumentado su ritmo cardiaco tras la ingestión del mismo. Pero se invalida si pensamos que los estados de ansiedad pueden provocar un estado cardiaco similar.

2. Prueba de la provocación sublingual. Se realizaba colocando una gota con solución que incluía el alergeno debajo de la lengua. Se esperaba una reacción física, pues se basaba en la teoría de que la absorción de sustancias ingeridas a través de la membrana mucosa sublingual basta para producir una reacción física moderada. Esta prueba es inválida, pues se observa que existen reacciones similares con una solución de otros alimentos no alergénicos.

3. Prueba de la provocación-neutralización. Este método ofrece diferentes variantes; en todo caso requiere la administración, por inyección o mediante gotas por vía sublingual, de dosis progresivamente más altas de la sustancia a ensayar. Se pretendía la aparición de cambios notorios al aumentar la dosis, y que desaparecerían al aumentar o disminuir la dosis. En caso positivo esta última dosis se emplearía para su posterior tratamiento.

Se invalidó esta prueba al comprobarse que con un placebo, se volvía a poner en evidencia el resultado.

4. Prueba de los alimentos citotóxicos, basado en la destrucción de diversos leucocitos al ponerlos en contacto con una solución alergénica del alimento del que se sospecha. Invalidada debido a que los resultados variaban de uno a otro día, además de detectarse numerosos falsos positivos.

5. Análisis capilar. Sirve para detectar tóxicidad de metales por análisis del faneras, pero no se ha demostrado que el pelo presente alguna sustancia que refleje ningún 
tipo de alergia alimentaria. Además, se observaron grandes discrepancias en los informes sobre réplicas de muestras duplicadas tomadas de la misma persona.

6. Otras pruebas de laboratorio. Se basan en el hecho de que están involucrados mecanismos inmunológicos en las reacciones alérgicas. Para ello, se utilizan células o complejos pertenecientes a la inmunidad: componentes del complemento, niveles séricos de distintos Ac's, recuentos de linfocitos, detección sérica de mediadores de la inflamación, para someterlos a tratamiento con el Ag. en cuestión. Aun hoy sigue sin demostrarse su utilidad al respecto.

Se siguen investigando nuevos métodos, a pesar de la inexistencia de pruebas convincentes. La presunta eficacia de otros dos métodos, la desensibilización potenciada por enzimas y la homeopatía están basados en análisis poco rigurosos.

De cualquier modo, los métodos expuestos continúan utilizándose en la medicina alternativa o tradicional.

Pruebas diagnósticas de enfermedad

El diagnóstico de cualquier intolerancia aun se basa en una prueba de provocación bien realizada, valorando siempre la relación beneficio frente al riesgo, sobre todo en pacientes con historial clínico grave.

Las bases sobre las que se establece el diagnóstico alergológico son las siguientes:

\section{Historia Clínica.}

Una historia clínica detallada y adecuada del paciente alérgico tiene la máxima importancia a la hora de detectar los posibles alergenos desencadenantes de la 
reacción. La época de los episodios, la frecuencia de los mismos, su carácter brusco, intenso o débil, así como el medio por el cual el enfermo acusa mejoría, pueden constituir una buena información que conduzca a la causa primordial.

Valoración de la Ig.E total sérica.

Las elevadas concentraciones de Ig E sérica constituyen un carácter añadido a la hora de inclinar el juicio diagnóstico hacia la existencia de una posible patología alérgica y, como se comentó anteriormente, los valores bajos no deben descartarla. Los valores de Ig E son variables en función del grado de exposición al alergeno, aunque esta Ig. podría estar elevada por otros procesos patológicos, como parasitosis, inmunodeficiencias, alteraciones hemáticas o renales y otras.

Identificación de los alergenos.

La identificación del alergeno puede efectuarse por distintos métodos:

1.-Métodos in vivo:

Pruebas de provocación.

Pruebas cutáneas.

2.-Métodos in vitro:

Pruebas biológicas.

Valoración de IgE específica.

Las pruebas de provocación consisten en la administración del alergeno supuestamente causal por la misma vía por la que normalmente penetra en el organismo. Estas pruebas son el método más idóneo y constituyen el sistema de diagnóstico más fiable, que conduce al diagnóstico etiológico. 
Este tipo de pruebas se reservan únicamente para casos en los que no se pueden realizar otros procedimientos diagnósticos, o en los que éstos no han proporcionado resultados satisfactorios.

Las pruebas cutáneas, son el método diagnóstico más empleado en alergología, pues a la facilidad del empleo, se une la claridad de los resultados. Hay tres variantes; Intradermorreacción -inyección de una pequeña solución del alergeno a examinar debajo de la epidermis-, Escarificación -se practica una pequeña incisión muy superficial y se deposita una gota de solución alergénica-, e inyección Epicutánea -se deposita el extracto del alergeno directamente sobre la piel-.

Los métodos biológicos consisten en colocar un extracto del presunto alergeno con basófilos del paciente en cuya superficie se encuentren fijadas moléculas de Ig E por receptores específicos de la reaginina. Si se produce el complejo inmunitario, sucederá desgranulación del basófilo que se detecta con tests específicos.

Valoración de la reagina Ig E circulante, que se establece por RAST -Radio Allergo Sorben Test-. Se utiliza cuando no pueden practicarse pruebas cutáneas. Es de gran fiabilidad y permite trabajar con un gran número de alergenos a la vez. Este método precisa un RIA -Radio Inmuno Assay -. Lo que varía es el uso de distintos marcadores (enzimáticos, fluorescentes, lumínicos, etc.).

\subsection{Interpretación de resultados: diagnosis}

Un buen diagnóstico se basa en el resultado de una prueba de provocación de una reacción por parte de la sustancia objeto de estudio, pero teniendo en cuenta una posible hipersensibilización del sujeto a dosis relativamente bajas de alergeno para así evitar reacciones no deseadas. Este diagnóstico se debe corroborar con operaciones complementarias, como pueden ser la biopsia intestinal -enfermedad 
celíaca-, pruebas para la detección de defectos enzimáticos -test de tolerancia a la lactosa-, o de fermentación intestinal excesiva -como la evaluación del contenido de H2 del aire espirado-. Incluso es necesario realizar comprobaciones por reacciones inmunológicas, como las pruebas cutáneas y pruebas de identificación de Ac's específicos a los alimentos.

Las pruebas cutáneas más precisas son la intradermorreacción y las punciones. Actualmente, las preparaciones que aportan mayor exactitud son las que incluyen extractos antigénicos de huevo, de pescados blancos, de varios tipos de frutos secos y de leche de vaca; patologías que abordaremos en breve. Sin embargo, son pocos los extractos alimentarios adecuados para ser utilizados en pruebas cutáneas, pero, de emplearse los extractos adecuados, los resultados de las pruebas cutáneas mediante punción o inyección intradérmica son sorprendentemente precisas y efectivas.

Como ya se citó, la prueba de laboratorio más importante para medir niveles séricos de Ig E frente a alimentos es la RAST, pero sigue siendo exacta la prueba de punción por lo que el RAST se emplea como confirmación a otros diagnósticos previos.

Finalmente, para diferenciar la intolerancia a los alimentos de otras alteraciones, resulta necesario tener en cuenta la existencia de diversas causas de anormalidades respiratorias, gastrointestinales o cutáneas. Dado que las reacciones adversas a los alimentos se deben frecuentemente a causas no inmunológicas, es importante considerar la posibilidad de que los síntomas que un individuo presenta puedan ser debidos a la presencia en los alimentos de toxinas o contaminantes que producen efectos toxicológicos, a agentes infecciosos intestinales o de otra naturaleza, a defectos enzimáticos (alactasia), o a reacciones no inmunológicas frente a aditivos alimentarios (como la tartrazina) que produzcan reacciones con efectos similares a los de las alergias. 
Características para el diagnóstico clínico de intolerancia y alergia a alimentos.

Los síntomas suelen desaparecer cuando se excluye el alimento de la dieta.

La reingestión del alimento reproduce los mismos síntomas, incluso cuando se administra de forma no reconocible.

Para el diagnóstico de la alergia, es necesaria la demostración adicional de que el alimento reacciona con las células o Ac.'s del sujeto.

\subsection{Cuadros clínicos de intolerancias y alergias}

En los casos más graves, pueden presentarse en minutos síntomas tales como vómitos y shock alérgico, junto con asma, caída brusca de la tensión arterial y urticaria extensa, característico de anafilaxia sistémica. La cantidad de alimento necesaria para desencadenar el ataque puede ser muy pequeña y, por ejemplo fragmentos minúsculos de nueces pueden ser suficientes para causar serios problemas que pueden comprometer la vida del individuo. Síntomas tales como dolor abdominal y estreñimiento son también relevantes en estas patologías.

La anafilaxia amenaza la vida y requiere el empleo inmediato de adrenalina o corticosteroides, líquidos infundidos por vía endovenosa y otras medidas de soporte vital.

Entre los efectos gastrointestinales destacados, son consecuencia de la malabsorción de grasas $\mathrm{y}$, con menor frecuencia, la pérdida de proteínas por el intestino. Los episodios menores y más infrecuentes pueden ser hemorragias que conllevan a la aparición de una anemia por falta de hierro y a bajos niveles de proteínas séricas, en pacientes que tienen problemas colaterales, como el asma y el eccema. También se ha 
de reseñar gastroenteritis eosinofílica. La diarrea grasa debida a la intolerancia a la leche de vaca y la intolerancia al gluten, ilustran quizás dos buenos ejemplos de estos síntomas.

Específicos de diversas patologías se produce la destrucción de tejido, resultando dañado el borde en cepillo de los enterocitos, como ocurre en la enfermedad celíaca o en la intolerancia a la lactosa, donde además, es concluyente la medida de H2. en el aire espirado, pues la degradación de la lactosa no absorbida por parte de la flora intestinal produce $\mathrm{H} 2$, que llega a los pulmones transportado por la sangre.

La observación de intolerancias frente a productos como el trigo y otros cereales, así como productos lácteos, café, té, cítricos y diversos vegetales, también provocan síntomas de tipo abdominal como los ya descritos.

Asimismo, el chocolate, cebollas, frutos secos, patatas y el alcohol pueden provocar problemas en algunas personas.

Las reacciones cutáneas a los alimentos son frecuentes en la infancia, y es probable que tras la ingestión de naranjas, aparezcan eccema y urticaria leves. Lesiones más serias aparecen en sensibilizaciones a la leche de vaca o al huevo de gallina, o urticaria de contacto desarrollada en niños al tocar pescado o huevos. La urticaria en los pacientes sensibilizados suele ser breve, remitiendo la sintomatología en unas pocas horas.

Los mecanismos de respuesta de la piel son bastante limitados, por ello la presencia de urticaria puede obedecer a múltiples causas.

El eccema alérgico de contacto es una manifestación de una hipersensibilidad de tipo IV, que está además caracterizada por eritema, vesiculación, exudación y escamación. 
El eccema puede ser producido por factores endógenos o externos; para el caso de este último puede ser el ya mencionado caso de urticaria de contacto.

En el tracto respiratorio se producirá siempre una sintomatología que es característica de procesos alérgicos ya avanzados, aunque es característico de alergias a huevos, pescado, frutos secos, además de la leche. Las bebidas de cola se encuentran entre los recientemente citados y que conducen al asma alérgico.

Se han relacionado episodios de asma potenciados por la interacción de dichos alimentos, más que porque sean capaces de producir el fenómeno, que lo son: es el caso de la alergia asociada al dióxido de azufre o al pescado.

Por último, también es frecuente la aparición de síntomas inespecíficos, como son: congestión, estornudo, cefaleas, migrañas y síntomas neurológicos, como en el caso del chocolate, la leche, derivados lácteos, el pescado, los huevos, los frutos secos y las judías.

\subsubsection{Leche de vaca}

La leche de vaca, comparada con la leche humana, posee un contenido en proteína y otros solutos desproporcionadamente alto, un contenido en aminoácidos desequilibrado y niveles inadecuados de ácidos grasos esenciales y otros nutrientes como el hierro y el zinc, que desaconsejan su empleo en niños menores de seis meses, debido a un riñón no bien preparado para filtrar la ingente cantidad de minerales presentes en ella, además de que la elevada presencia de fosfatos puede resultar en bruscas disminuciones de calcio, lo que puede llevar al extremo de la deficiencia de hierro, vitamina $\mathrm{C}$ y vitamina $\mathrm{D}$. 
Debido al alto índice de afectaciones gastrointestinales y de otra naturaleza, se han establecido programas de investigación, destinados al diseño de preparaciones de leche de vaca mejor tolerada.

Se conoce desde antiguo la implicación directa que tiene la leche de vaca en alteraciones gástricas y erupciones cutáneas. También por su contenido en lactosa, no es tolerada por los individuos que presenten deficiencia de lactasa, además de ser importante en la transmisión de infecciones.

Es preciso reseñar que la alta incidencia de alergias o intolerancias a la leche de vaca se da principalmente en niños lactantes, pues a esa temprana edad su sistema renal no está perfectamente funcional y además, la leche es el alimento por excelencia de su nutrición. En el caso de adultos es más improbable, y se suele desarrollar a edades avanzadas.

Los principales alergenos de la leche de vaca son la beta-lactoglobulina, la alfa y betacaseína y la alfa-lactalbúmina. Aunque la beta-lactoglobulina representa un 10\% de las proteínas totales, es un potente alergeno para los lactantes humanos, pues resiste la acción gástrica y es la única que llega al intestino íntegra, lo cual supone que el lugar de degradación y absorción es el mismo intestino.

Reseñar que no es tan habitual entre los alérgicos la presencia de cantidades elevadas de Ig E sérica, sino de Ig G, por causas que están siendo objeto de profundo estudio.

Como el riesgo a padecer estos fenómenos es creciente, se tratará de indagar en la leche de otros animales las distintas proporciones de sus constituyentes, pretendiendo prevenir la sintomatología, pero aparecen otros problemas tales como que, en muchos casos, resulta una dieta desequilibrada, como ocurre en el caso de la leche de cabra, en la que sus constituyentes no están en una proporción adecuada. 
Además, son frecuentes las reacciones cruzadas entre las proteínas de la leche de vaca y la de otros animales y los lactantes con intolerancia a la leche de vaca pueden desarrollar sensibilidad a cualquiera de estas leches, ya de forma inmediata o después de un intervalo adecuado.

Por otra parte, los métodos actuales de procesado de la leche incluyen la homogeneización, la pasteurización, la esterilización en autoclave o por tratamientos térmicos ultra altos y la hidrólisis con cultivos lácticos.

Con respecto a estos procesos, se ha sugerido que, en los niños sensibilizados, la leche pasteurizada $\mathrm{u}$ homogeneizada puede producir, en ocasiones, reacciones cutáneas más graves que la leche no tratada y que pequeñas cantidades pueden ser capaces de producir una reacción clínica. Con respecto al tratamiento térmico, la desnaturalización no es capaz, por si misma, de liberar a la leche de propiedades sensibilizantes, debido a que, a diferentes temperaturas el proceso es capaz de desnaturalizar unas proteínas alergénicas lo suficiente para que no se fijen a la Ig E pero no otras, pues sus fragmentos aun conservarán la capacidad de fijarse a los Ac. IgE. Dada la capacidad con que las proteínas desnaturalizadas se degradan en el tubo digestivo, puede anticiparse que el tracto intestinal otorgará algún grado de protección. Sin embargo, el proceso térmico no ha proporcionado resultados satisfactorios a la hora de obtener preparaciones lácteas no sensibilizantes.

En los hidrolizados de proteínas lácteas, tan utilizados como sustitutos de la leche materna, se ha tendido a utilizar extractos de proteína de soja, tanto en el tratamiento como en la prevención de intolerancia a la proteína de la leche, pero no han podido prevenir las alteraciones mediadas por IgE en niños previamente sensibilizados a la proteína de leche de vaca y, en muchos casos, han sido causantes de reacciones. En cambio, los hidrolizados enzimáticos de proteínas han resultado ser eficaces parcialmente: es válido para el caso de intolerancia a proteínas de la leche, pero 
ninguno de estos preparados está exento del riesgo de provocar reacciones en niños alérgicos a la leche de vaca, que varía con el grado de digestión enzimática, con las enzimas utilizadas y con el procesado subsiguiente.

Por último, la tendencia actual se basa en la degradación de las proteínas de la leche de vaca por enzimas proteolíticas (pepsina y tripsina o quimotripsina), hecho que puede ser útil en niños sensibilizados. Por ello, cada vez se usan más las preparaciones proteolizadas. Sin embargo, como el grado de proteolisis varía con los distintos preparados, asimismo variará el grado de seguridad a dichos preparados.

Finalmente, existen otras alternativas al uso de la leche de vaca y sus derivados: entre ellas se encuentran las mezclas basadas en proteína de carne de vacuno o de pollo reforzadas con carbohidratos, grasa, vitaminas y minerales.

Otra alternativa, ya comentada, es el empleo de soja. La leche de soja es tradicionalmente un extracto acuoso de habas o de harina de soja, sin desengrasar, que ha sido tratada térmicamente y filtrada con objeto de destruir sus toxinas. Es una opción de elección porque tiene la ventaja de poseer un sabor y olor aceptables, además de ser fácilmente costeable.

Para que los preparados lácteos sean seguros, deben ser cuidadosamente reconstituídos, pero aun no se han superado los problemas que representan su costo y el sabor no muy apetecible que algunos de ellos tienen.

\subsubsection{Sensibilidad al gluten y enfermedad celiaca}

La enfermedad celíaca suele aparecer en la primera infancia, tras la introducción de cereales en la dieta. La mayor parte de los niños celíacos son diagnosticados antes de cumplir los dos años de edad. 
Las manifestaciones clínicas clásicas son las de un niño con desarrollo no normal, con diarrea grasa, abdomen abultado, musculatura con cierta atonía, debilidad y mal carácter.

La tendencia a que esta enfermedad se manifieste parece seguir un patrón hereditario, por tanto, podría definirse como "enfermedad genéticamente determinada en la que se presenta una reacción anómala a alguna de las proteínas de reserva -prolaminas- del trigo, cebada, avena, arroz $u$ otros y que dañan la pared del intestino delgado interfiriendo la absorción de algunos nutrientes o todos en las partes intestinales afectadas".

Diversos estudios experimentales daban cuenta de este hecho, además de que tras la instauración de una dieta constituída fundamentalmente por patatas, bulbos de tulipán y repollo, resultaba beneficiosa para los niños con dicha patología, aunque producía pérdidas de peso en los demás. Numerosas aportaciones novedosas fueron completando la definición y ahondando en la descripción de la patología en su conjunto. En 1953 se demostró que era el gluten, concretamente la gliadina el componente que constituía el factor tóxico del trigo que dañaba la pared intestinal de los pacientes con enfermedad celíaca. Con la detección de este componente en otros alimentos, se procedió a excluirlo de la dieta de dichos pacientes.

El gluten es una sustancia albuminoide de reserva para la semilla, adhesiva, insoluble en agua, que junto con el almidón forman el componente mayoritario de la harina de los cereales. La naturaleza del gluten se reconoce por el empleo del aleurómetro. Estructuralmente está constituido por dos materias de naturaleza proteica: la gliadina y la gluteína. Posee la propiedad de ser atacable únicamente en el intestino, por lo que se ha empleado como material de recubrimiento en formas orales gastrorresistentes. 
Entre las pretensiones en el campo de la investigación se busca identificar qué característica de la molécula es la responsable de su acción tóxica, pues de conocerse, podrían ensayarse variedades de cereales que aun conteniendo proteínas de reserva, careciesen del componente tóxico.

En este sentido, se sabe que las proteínas de esta gran familia botánica que constituyen las gramíneas poseen una particular semejanza, dado que se hallan entre si emparentados genéticamente: en ellas, las proteínas de reserva no poseen una función específica en el grano, constituyen un almacén de nutrientes y energía y están formados por albúminas, globulinas y prolaminas de distintos tipos. De éstas, las prolaminas son las que más han sido estudiadas.

Las prolaminas son la reserva de Nitrógeno durante la germinación y están constituidas mayoritariamente por un $17 \%$ de Pro -prolina- y un $40 \%$ de Gln glutamina-. En los distintos géneros y especies de esta familia, las prolaminas reciben nombres muy distintos (Gliadina en el caso del trigo, Secalina en el del centeno, Hordeína, Avenina, Zeína, para la cebada, avena y maíz, respectivamente), pero están suficientemente emparentados como para que en el hombre causen respuestas inmunológicas, que muestran una considerable reactividad cruzada entre unas y otras. En el trigo la alfa-gliadina es tóxica para los pacientes celíacos, y los metabolitos que son producto de la proteolisis con la pepsina, también lo son.

Respecto a la naturaleza de la sensibilidad al gluten, aun no se conoce la causa de la enfermedad: si es producida por un defecto enzimático, o si existe intervención del sistema inmune o una acción adhesiva sobre el epitelio intestinal. Con una dieta exenta de gluten el aparato enzimático recupera su actividad normal en líneas generales. 
Parece más razonada la explicación inmunitaria, especialmente porque la provocación con gluten conduce rápidamente a la presencia en la mucosa intestinal de células T, sin embargo, los niveles de antigliadina Ig A e Ig G solo presentan niveles elevados si se presenta gluten en la dieta, en caso contrario los niveles descienden hasta la normalidad, con lo que se tiende a pensar que tal vez el fenómeno de infiltración de células T sea un proceso secundario.

Métodos de diagnóstico más recientes, como la prueba de fluorescencia avalan esta hipótesis.

También se ha sugerido que la adhesión de la gliadina al epitelio intestinal solo se da en pacientes con predisposición a sufrir la enfermedad. Sin embargo, aunque pueden producirse estas "moléculas de adhesión" para fijar la gliadina, los intentos de demostrar que pueden fijarse al tejido vivo no han tenido éxito.

En cuanto a las características clínicas, la presentación de la enteropatía por gluten se manifiesta por la aparición de diarrea, debilidad y dilatación abdominal. En niños puede ir precedido de vómitos y síntoma acusado de pérdida de apetito. En otros casos se presenta malnutrición proteica, retraso en el crecimiento e incapacidad de ganar peso. En adultos, en casi todos los casos no suelen diagnosticarse, dada la levedad de la patología o ser procesos asintomáticos. Estudios epidemiológicos indican que hay picos de incidencia a edades de unos 40 años en mujeres y 60 - 78 años en los hombres. La proporción hombres : mujeres es 1,26:1.

El principal método de diagnóstico es en la actualidad la biopsia y búsqueda de las lesiones específicas en el yeyuno del epitelio intestinal, lo que ha contribuído a relacionar otras posibles patologías con ésta y cuyas asociaciones potencian la sintomatología de esta enfermedad. 
Hay que destacar que no todas las intolerancias al gluten están relacionadas con lesiones de la mucosa intestinal y se han descrito casos no celíacos en los que se manifiestan los síntomas sin que exista lesión alguna del recubrimiento intestinal. El hecho de que la lesión intestinal en individuos celíacos se produzca en la parte inicial del intestino trae como consecuencia una síntesis reducida de enzimas de la mucosa tal es el caso de disacaridasas y peptidasas y un descenso en la producción de hormonas intestinales (VIP -Péptido Inestinal Vasoactivo). También se dan cambios en el pH del contenido intestinal, que se hace más alcalino, lo que puede dificultar la absorción de medicamentos y nutrientes, y a la larga, facilitar que conduzca a estados deficitarios. La carencia de enzimas de la mucosa produce, con cierta frecuencia, intolerancia a la lactosa, que es causa en sí misma de diarrea y de síntomas de colon irritable. Se produce también una secreción activa de Na en la porción más alta del yeyuno, que no siempre puede compensarse mediante un aumento de la absorción de agua y electrolitos en la porción distal del intestino delgado. Como consecuencia de la diarrea, hay una mayor pérdida de K y pueden darse pequeñas pérdidas de Zn y Mg. Los sujetos que presentan pérdidas intensas de electrolitos pueden desarrollar letargia, debilidad, irritabilidad, confusión, pérdida de memoria, espasmos musculares, incoordinación, pérdida del gusto e infertilidad. Las alteraciones electrolíticas, si no se corrigen, pueden conducir a alteraciones de los túbulos renales y a un incremento de la excreción urinaria durante la noche. En los casos no tratados, suele disminuir la absorción de vitamina $\mathrm{D} y$, a causa del exceso de grasa en las heces, podría también reducirse la absorción de Ca. La debilidad muscular, debida a la deficiencia de vitamina $\mathrm{D}$ es un síntoma temprano, aunque ocasional. Con el tiempo es frecuente la pérdida de matriz ósea por la carencia de vitamina D.

Para terminar, se reconoce en la enfermedad celíaca de larga duración un aumento de la incidencia de las enfermedades malignas, así como neuropatías que no remiten con la instauración de dietas exentas de gluten. 
Para todas las manifestaciones clínicas de intolerancia al gluten, el único tratamiento existente es su eliminación de la dieta.

Hay una reglamentación del Código Alimentario que regula las cantidades máximas de este alimento, dada la dificultad de su exclusión completa, pues se utiliza ampliamente en la industria alimentaria. En estos pacientes se ha de llevar una disciplina exhaustiva de sus ingestas, pues las interacciones relacionadas con esta patología pueden desembocar en otras intolerancias, como es el caso de la Intolerancia a la lactosa, por inactivación de las lactasas del intestino delgado.

\section{Nuevas expectativas $y$ tendencias actuales}

\subsection{Errores dietéticos}

La tendencia a diagnosticar con excesiva facilidad reacciones de intolerancia a los alimentos, ha provocado un control inadecuado de diversos diagnósticos no objetivos que llevan al incorrecto establecimiento de una patología de tipo alérgico.

En la gran mayoría de los pacientes que desarrollan reacciones a los alimentos, es relativamente fácil de identificar y evitar el alimento o el par de alimentos que les producen problemas. Sin embargo, las reacciones más alarmantes son las que implican alergia de tipo inmediato, que hace necesario indagar los componentes de, por ejemplo, salsas y aderezos para ensalada, el método de cocinado o los ingredientes de pasteles y platos precocinados. Habitualmente suelen estar implicados: pescados, mariscos, huevos, frutos secos o leche, aunque en ocasiones pueden estarlo el trigo, la soja, la semilla de sésamo, los productos derivados de la uva -entre ellos el vino y el vinagre, las especias -la mostaza- y otros ya relacionados.

El paciente que sufre una forma de reacción insidiosa y menos inmediata a los alimentos, es fácil que encuentre más dificultades para identificar los productos 
responsables. La primera de estas dificultades deriva de la existencia de un número relativamente limitado de métodos de diagnóstico y del escepticismo que, con frecuencia, despierta en los médicos, en los dietistas e incluso en los amigos y conocidos. Sin embargo, para evitar las reacciones clínicas a los alimentos se necesita una indagación cuidadosa de los platos cocinados cuando se come fuera de casa. En determinadas ocasiones se hace evidente un absoluto cuidado de los alimentos a ingerir, pues en el caso de los individuos muy sensibilizados, puede ser causa desencadenante de anafilaxia sistémica.

Por otra parte, se hace evidente la importancia del establecimiento de dietas, cuya finalidad es puramente preventiva, pues no existen aun tratamientos eficaces en la manipulación de los alimentos que excluyan los posibles alergenos de los mismos. La instauración de dietas encaminadas a la eliminación de alimentos conlleva riesgos, junto con beneficios y debe ir precedida siempre de los métodos diagnósticos tratados en los apartados anteriores. Cuando se prescriben dietas restrictivas muy drásticas sobre la base del historial clínico, combinados con los que llamamos pruebas diagnósticas no ortodoxas, pueden conducir estas imperfecciones a errores en la instauración de dietas por no disponer de un diagnóstico correcto. En cualquier caso, la valoración del estado nutricional de un paciente y sus necesidades constituye, idealmente, el campo de acción de los dietistas, que deberán calcular las necesidades en vitaminas y minerales teniendo en cuenta las recomendaciones dietéticas establecidas. Las elección de los alimentos debe efectuarse teniendo en cuenta consideraciones tanto cualitativas como cuantitativas. En el caso de que la dieta sea inadecuada, deben suministrarse suplementos minerales y vitamínicos y de otras sustancias que puedan ser deficitarias. En los niños debe efectuarse un control regular de su altura y de su peso, para compararlos con las tablas estándares nacionales, al objeto de detectar cualquier signo de defecto del desarrollo o de excesivo adelgazamiento, pues existen patologías asociadas a defectos en el 
crecimiento por ellos son útiles herramientas diagnósticas, como el caso de individuos celíacos.

\subsection{Avances en el estudio de pruebas diagnósticas}

Lo primordial debe ser la prevención y, para ello, lo básico es un diagnóstico temprano y certero; para posteriormente evitar la exposición al alergeno. Hoy en día ya hay formas de tratar estas afecciones, por medio de medicamentos específicos para distintas estaciones o periodos de mayor incidencia, así como para los primeros estadios de las alergias. Los tratamientos inmunológicos se basan en tratar de reducir los niveles de Ig.E presente en el individuo en cuestión. Hay varios procedimientos encaminados a la consecución de esto, basados en inducir tolerancia frente al Ag.; uno de ellos es la desensibilización, vacuna o inmunoterapia, que consiste en administrar por vía subcutánea cantidades pequeñas pero crecientes del alergeno en un periodo de tiempo regular y establecido según las pautas de administración. Como resultado, la concentración de Ig E específica disminuye, y suelen aumentar los títulos de IgG quizás inhibiendo la producción de Ig E y favoreciendo al producción de $\operatorname{Ig}$ G, que no está relacionado con procesos alérgicos.

Los efectos beneficiosos de la desensibilización pueden ocurrir en horas, mucho antes que los cambios en los niveles de Ig E.. Aunque se desconoce el mecanismo, este método evita respuestas anafilácticas agudas frente a Ag.'s proteicos o fármacos vitales. Pero no es tan eficaz para el tratamiento de los síntomas de la anafilaxia.

Otros métodos que se hallan en fase experimental se apoyan en el estudio de los detalles que faltan por conocer de los mecanismos de acción del sistema inmunitarios. Por ejemplo: una de las áreas más investigadas se centran en una fase precoz de la respuesta alérgica: la regulación de la síntesis de Ig E. Otros estudios se centran en los efectos más que en la síntesis de IgE, rastrean las complejas vías de 
transducción de señales de granulocitos: la serie de pasos a través de los cuales el entrecruzamiento de moléculas de $\operatorname{IgE}$ de la superficie celular desemboca en la liberación de las sustancias que inducen la enfermedad, es decir, los mediadores biológicamente activos.

Finalmente, hay nuevos métodos, pero están en fase experimental. Uno de ellos consiste en promover el desarrollo de LTH, mediante administración de IFN. Otro de ellos, se basa en evitar la activación de la célula $\mathrm{T}$ mediante el tratamiento con péptidos inmunodominantes de alérgenos naturales, por la unión a moléculas de clase II del MHC.

\subsection{Repercusiones económicas}

La industria farmacéutica fija grandes expectativas en líneas de investigación, destinando sumas cuantiosas. Se calcula que el mercado farmacéutico mundial se apoya en cantidades cercanas al billón de pesetas. Este enorme interés que suscitan las intolerancias e hipersensibilidades tiene su origen en los progresos realizados dentro del campo de la inmunología, donde se avanza con rapidez en el desenvolvimiento de los mecanismos inmunitarios. Se buscan fármacos con una selectividad excepcional, dado que se pretende una respuesta frente a algunos tipos de mediadores o incluso células inmunitarias específicas. La gran dificultad en este campo justifica las grandes inversiones establecidas para una mejor calidad de vida de los pacientes asmáticos, que salvo remisión espontánea con el empleo de las pautas de los tratamientos más novedosos, estarán identificados con un tratamiento a largo plazo. 


\section{Bibliografía}

1. ABBAS, K. Y LITCHMAN, A. H. Inmunología celular y molecular. Interamericana Mc Graw Hill. $2^{\text {a }}$ Ed.

2. LESSOF, M. H. Alergia e intolerancia a los alimentos. Ed. Acribia, S.A. $1^{\text {a }}$ Ed.

3. VARIOS AUTORES. Comunicación celular. Objetivo de la nueva farmacología. Investigación y Ciencia, nº 195 Dic. 1992.

4. TRESGUERRES, J.A.F. Fisiología Humana. Ed. Mc Graw-Hill, 1ª Ed. 1992.

5. ROITT BLACKWELL, I.M. Essential inmunology, Scientific publication, $7^{\mathrm{a}}$ Ed. 1991.

6. Autor. Specialization, tolerance, memory, competition, latency and style among Tcells. An. Rev. of Inmunology. Vol I, 1-12, 1992.

7. REPPETO, M. Toxicología avanzada. Ed. Acribia, 1996.

8. AGUILERA FRANCO, M. Alergias alimentarias: Introducción a su estudio. 1993.

9. METTCALFE, D.D. Food allergy: adverse reactions to foods and food additions.

10. Editorial. Prevention in allergy. Allergol-inmunopathol. Madrid 1995. Jul -Ago.; 23(4):147.

11. NOSSAL, SIR GUSTAV. Sistema inmunitario: entre la vida y la muerte . Investigación y Ciencia, Nov. 1993206. 
12. WEISSMAN, IRVING L Y COOPER, M. D. Formación y desarrollo del sistema inmunitario. I y C, Nov. 1993, 206.

13. MARRACK, P. Y KAPPLER, J.W. Recomocimiento del propio organismo por el Sistema inmunitario. I y C, Nov. 1993.

14. JANEWAY, CHARLES A. Reconocimiento inmunitario de cuerpos extraños. I. y C., Nov. 1993206.

15. PAUL , W. E. Enfermedades infecciosas y Sistema inmunitario. I. y C. , Nov. 1993 206.

16. STEINMAN, L. Autoinmunidad. I. y C. , Nov. 1993206.

17. LICHTENSTEIN, L. M. La alergia y el sistema inmunitario. I y C, Nov. 1993206.

18. MITCHISON. A. ¿Sobreviviremos? I y C, Nov. 1993206.

19. ROBBINS. Patología estructural y funcional. Ed Mc Graw-Hill, 1994.

20. ELVERDiN GARCÉS, C. PÉRZ MONTERO, M. P. Alergias. Programa de formación continuada. Educación sanitaria. Información al farmacéutico. Coleg. Oficial de Farm. de Navarra. 